\title{
Synthesis and Anti-tumor Activities of Novel Oxazinyl Isoflavonoids
}

\author{
Dun Wang, ${ }^{* a}$ Like Hou, ${ }^{a}$ Lirong $\mathrm{Wu}^{,}$, and $\mathrm{Xin} \mathrm{Yu}^{b}$ \\ ${ }^{a}$ College of Pharmacential Engineering, Shenyang Pharmaceutical University; Shenyang 110016, China: and \\ ${ }^{b}$ Medical \& Regulatory Affairs Department, Fresenisu Kabi (China) Co., Ltd., BD; Beijing 100007, China. \\ Received December 7, 2011; accepted January 16, 2012; published online February 1, 2012
}

The design, synthesis and biological evaluation of a novel series of oxazinyl isoflavonoids is described. Several analogs were shown to exhibit growth inhibitory effects against SKOV-3, DU-145 and HL-60 human colon cancer cell lines with $\mathrm{IC}_{50}$ values in the micromolar range. The cellular potency of compounds $7 \mathrm{e}$ and $12 \mathrm{~h}$ were found to have greater in vitro inhibitory activities than phenoxodiol, the parental compound currently in late-stage clinical trials for the treatment of cancer. The results shown are suitable for further lead optimization.

Key words anti-tumor activity; oxazinyl isoflavonoid compound; synthesis

With the changes in the current living environment, cancer has become the second leading cause of death in developed countries. Over 1 million cases of cancer occur in the United States annually, and cancer-related deaths are estimated to reach 12 million worldwide by the year 2015. .) $^{\text {Therefore, a }}$ new generation of useful anticancer chemotherapy agents is becoming more urgent.

Isoflavonoids, which are present in vegetables, beans, peas, and other legumes, are one of the principal plant hormones known to possess the potential to regulate plant cycle kinetics and death and may have similar effects in animals. A number of naturally occurring plant hormones, including isoflavonoids and particularly daidzein and genistein, have been shown to exhibit biological activity in mammalian cells by regulating various functions, such as cell-cycle progression, mitotic arrest and apotosis. ${ }^{2,3)}$ Specifically, genistein was well tolerated, with minimal toxicity, in normal tissues, and its effects were seen in multiple tumor types, including prostate, breast and pancreatic tumors. However, its limited bioavailability and extensive metabolism led to difficulties in attaining adequate plasma concentrations, resulting in limited utility and dissemination in the clinic. ${ }^{4)}$ For phenoxodiol (2H-1-benzopyran7-ol, 3-[4-hydrophenyl], Fig. 1), an analogue of genistein, a broad range of activities against human cancer cells was found, inducing mitotic arrest $\left(\mathrm{G}_{1}\right.$ phase of mitosis), terminal differentiation and apoptosis. Due to these findings, phenoxo-

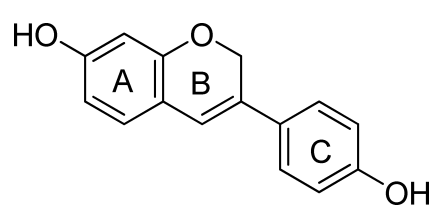

Fig. 1. The Structure of Phenoxodiol<smiles>c1ccc(C2COc3c(ccc4c3CNCO4)C2)cc1</smiles>

I<smiles>C1=C(c2ccccc2)COc2c1ccc1c2CNCO1</smiles>

II<smiles>O=C1c2ccc3c(c2OCC1c1ccccc1)CNCO3</smiles>

III<smiles>C1=C(c2ccc3c(c2)CNCO3)COc2ccccc21</smiles>

IV

Fig. 2. Four Type Target Compounds 

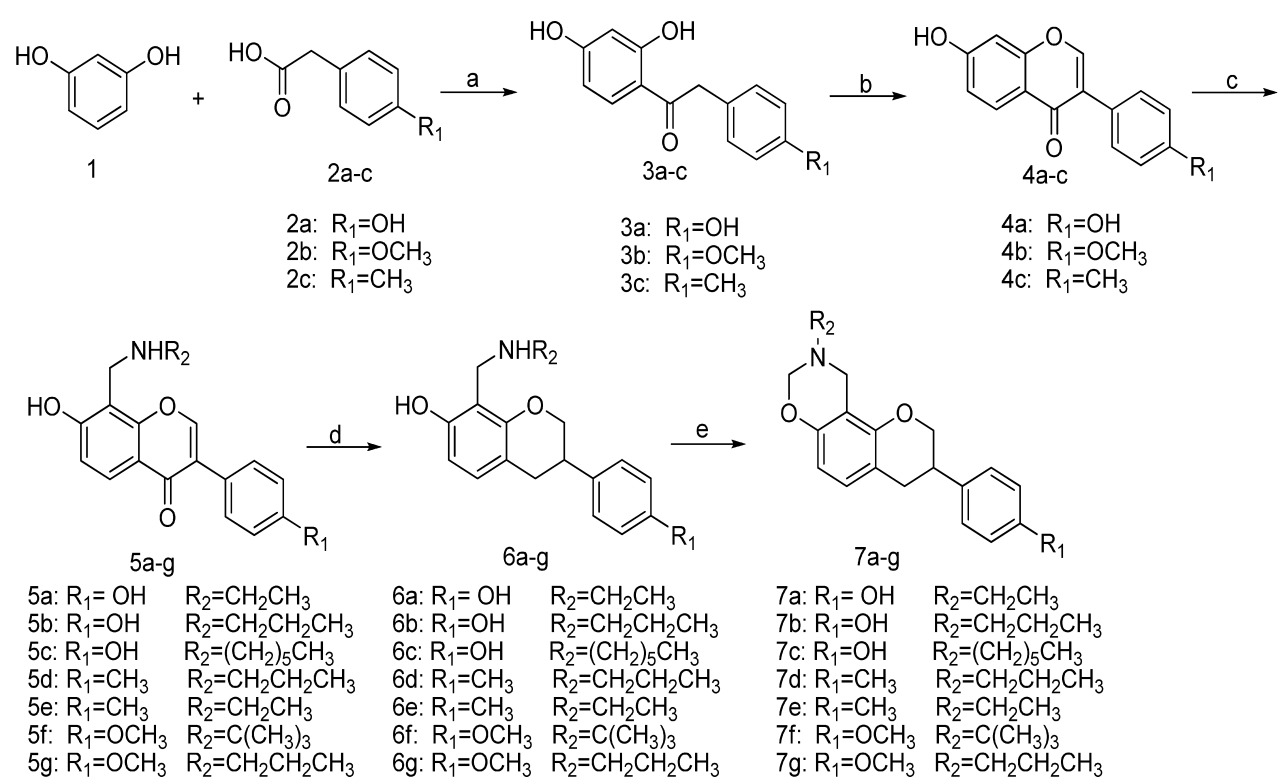

Reaction conditions: (a) $\mathrm{BF}_{3} \cdot \mathrm{Et}_{2} \mathrm{O} / 80^{\circ} \mathrm{C}$; (b) $\mathrm{CH}_{3} \mathrm{SO}_{2} \mathrm{CI} / \mathrm{DMF}, 50-70^{\circ} \mathrm{C}$; (c) $\mathrm{R}_{2} \mathrm{NH}_{2}, 37 \% \mathrm{HCHO}, 1,4$-dioxane, $45-70^{\circ} \mathrm{C}$; (d) $10 \% \mathrm{Pd}^{\circ} \mathrm{C}, \mathrm{HCOONH}_{4}, \mathrm{CH}_{3} \mathrm{COOH}, 110^{\circ} \mathrm{C}$; (e) $(\mathrm{HCHO})_{n}, \mathrm{KOH}, \mathrm{CH}_{3} \mathrm{OH}$

Chart 1. The Synthesis of Oxazinyl Isoflavonoid Compounds $\mathbf{7 a - g}$

Table 1. In Vitro Growth Inhibitory Effects of the Target Compounds 7a-18d in Three Human Cancer Cell Lines

\begin{tabular}{|c|c|c|c|c|c|}
\hline \multirow{2}{*}{ Compd. } & \multirow{2}{*}{$\mathrm{R}_{1}$} & \multirow{2}{*}{$\mathrm{R}_{2}$} & \multicolumn{3}{|c|}{ In vitro $\mathrm{IC}_{50}(\mu \mathrm{M})$} \\
\hline & & & HL60 & SKOV-3 & DU-145 \\
\hline $7 a$ & $\mathrm{OH}$ & $\mathrm{CH}_{2} \mathrm{CH}_{3}$ & 0.123 & 19.505 & 22.693 \\
\hline $7 b$ & $\mathrm{OH}$ & $\mathrm{CH}_{2} \mathrm{CH}_{2} \mathrm{CH}_{3}$ & 11.86 & 17.131 & 41.585 \\
\hline $7 \mathrm{c}$ & $\mathrm{OH}$ & $\left(\mathrm{CH}_{2}\right)_{5} \mathrm{CH}_{3}$ & 2.185 & 13.206 & 7.706 \\
\hline $7 d$ & $\mathrm{CH}_{3}$ & $\mathrm{CH}_{2} \mathrm{CH}_{2} \mathrm{CH}_{3}$ & 4.645 & 23.155 & 20.096 \\
\hline $7 e$ & $\mathrm{CH}_{3}$ & $\mathrm{CH}_{2} \mathrm{CH}_{3}$ & 4.809 & 27.04 & 16.953 \\
\hline $7 f$ & $\mathrm{OCH}_{3}$ & $\mathrm{C}\left(\mathrm{CH}_{3}\right)_{3}$ & 0.763 & 8.132 & 9.113 \\
\hline $7 \mathrm{~g}$ & $\mathrm{OCH}_{3}$ & $\mathrm{CH}_{2} \mathrm{CH}_{2} \mathrm{CH}_{3}$ & 2.195 & 16.784 & 21.591 \\
\hline $12 \mathrm{a}$ & $\mathrm{OH}$ & $\mathrm{CH}_{2} \mathrm{CH}_{2} \mathrm{CH}_{3}$ & 7.11 & 23.173 & 30.108 \\
\hline $12 b$ & $\mathrm{OCH}_{3}$ & $\mathrm{CH}_{2} \mathrm{CH}_{2} \mathrm{CH}_{3}$ & 4.55 & 21.613 & 23.500 \\
\hline $12 \mathrm{c}$ & $\mathrm{OCH}_{3}$ & $\left(\mathrm{CH}_{2}\right)_{5} \mathrm{CH}_{3}$ & 5.89 & 31.984 & 14.379 \\
\hline $12 d$ & $\mathrm{CH}_{3}$ & $\mathrm{CH}_{2} \mathrm{CH}_{3}$ & 2.614 & 60.008 & 39.639 \\
\hline $12 \mathrm{e}$ & $\mathrm{CH}_{3}$ & $\mathrm{CH}_{2} \mathrm{CH}_{2} \mathrm{CH}_{3}$ & 1.006 & 67.25 & 39.668 \\
\hline $12 \mathrm{f}$ & $\mathrm{OCH}_{3}$ & $\mathrm{CH}_{2} \mathrm{CH}_{3}$ & 5.50 & 22.270 & 27.683 \\
\hline $12 \mathrm{~g}$ & $\mathrm{OH}$ & $\mathrm{CH}_{2} \mathrm{CH}_{3}$ & 5.15 & 28.554 & 14.018 \\
\hline $12 \mathrm{~h}$ & $\mathrm{OCH}_{3}$ & $\mathrm{CH}\left(\mathrm{CH}_{3}\right)_{2}$ & 3.04 & 7.483 & 9.101 \\
\hline $12 \mathrm{i}$ & $\mathrm{OH}$ & $\mathrm{CH}\left(\mathrm{CH}_{3}\right)_{2}$ & 1.78 & 11.772 & 8.030 \\
\hline $12 \mathrm{j}$ & $\mathrm{OH}$ & $\left(\mathrm{CH}_{2}\right)_{5} \mathrm{CH}_{3}$ & 3.16 & 16.577 & 18.395 \\
\hline $12 \mathrm{k}$ & $\mathrm{OCH}_{3}$ & $\mathrm{CH}_{3}$ & 1.859 & 24.398 & 20.932 \\
\hline 121 & $\mathrm{OH}$ & $p-\mathrm{C}_{6} \mathrm{H}_{4} \mathrm{CH}_{3}$ & 8.14 & $>100$ & $>100$ \\
\hline $12 \mathrm{~m}$ & $\mathrm{OCH}_{3}$ & $p-\mathrm{C}_{6} \mathrm{H}_{4} \mathrm{CH}_{3}$ & 17.404 & 61.102 & 65.856 \\
\hline $12 n$ & $\mathrm{CH}_{3}$ & $p-\mathrm{C}_{6} \mathrm{H}_{4} \mathrm{CH}_{3}$ & 5.616 & $>100$ & $>100$ \\
\hline $13 a$ & $\mathrm{OH}$ & $\mathrm{CH}_{2} \mathrm{CH}_{2} \mathrm{CH}_{3}$ & 55.788 & 93.827 & $>100$ \\
\hline $13 \mathrm{~b}$ & $\mathrm{OCH}_{3}$ & $\mathrm{CH}_{2} \mathrm{CH}_{2} \mathrm{CH}_{3}$ & $>100$ & $>100$ & $>100$ \\
\hline $13 \mathrm{c}$ & $\mathrm{OCH}_{3}$ & $\left(\mathrm{CH}_{2}\right)_{5} \mathrm{CH}_{3}$ & 23.81 & 7.432 & 58.817 \\
\hline 13d & $\mathrm{CH}_{3}$ & $\mathrm{CH}_{2} \mathrm{CH}_{3}$ & 52.92 & 70.893 & 82.857 \\
\hline $13 \mathrm{e}$ & $\mathrm{CH}_{3}$ & $\mathrm{CH}_{2} \mathrm{CH}_{2} \mathrm{CH}_{3}$ & $>100$ & $>100$ & $>100$ \\
\hline $18 \mathrm{a}$ & - & $\mathrm{CH}_{2} \mathrm{CH}_{3}$ & 3.52 & 34.416 & 27.649 \\
\hline $18 \mathrm{~b}$ & - & $\mathrm{CH}_{2} \mathrm{CH}_{2} \mathrm{CH}_{3}$ & 1.796 & 35.896 & 22.037 \\
\hline $18 \mathrm{c}$ & - & $\mathrm{CH}_{3}$ & 1.569 & 39.338 & 23.371 \\
\hline 18d & - & $\mathrm{CH}\left(\mathrm{CH}_{3}\right)_{2}$ & 3.121 & 25.467 & 11.976 \\
\hline Cisplatin & & & 12.08 & 32.15 & 28.42 \\
\hline Phenoxodiol & & & 35.102 & 30.558 & 21.03 \\
\hline
\end{tabular}



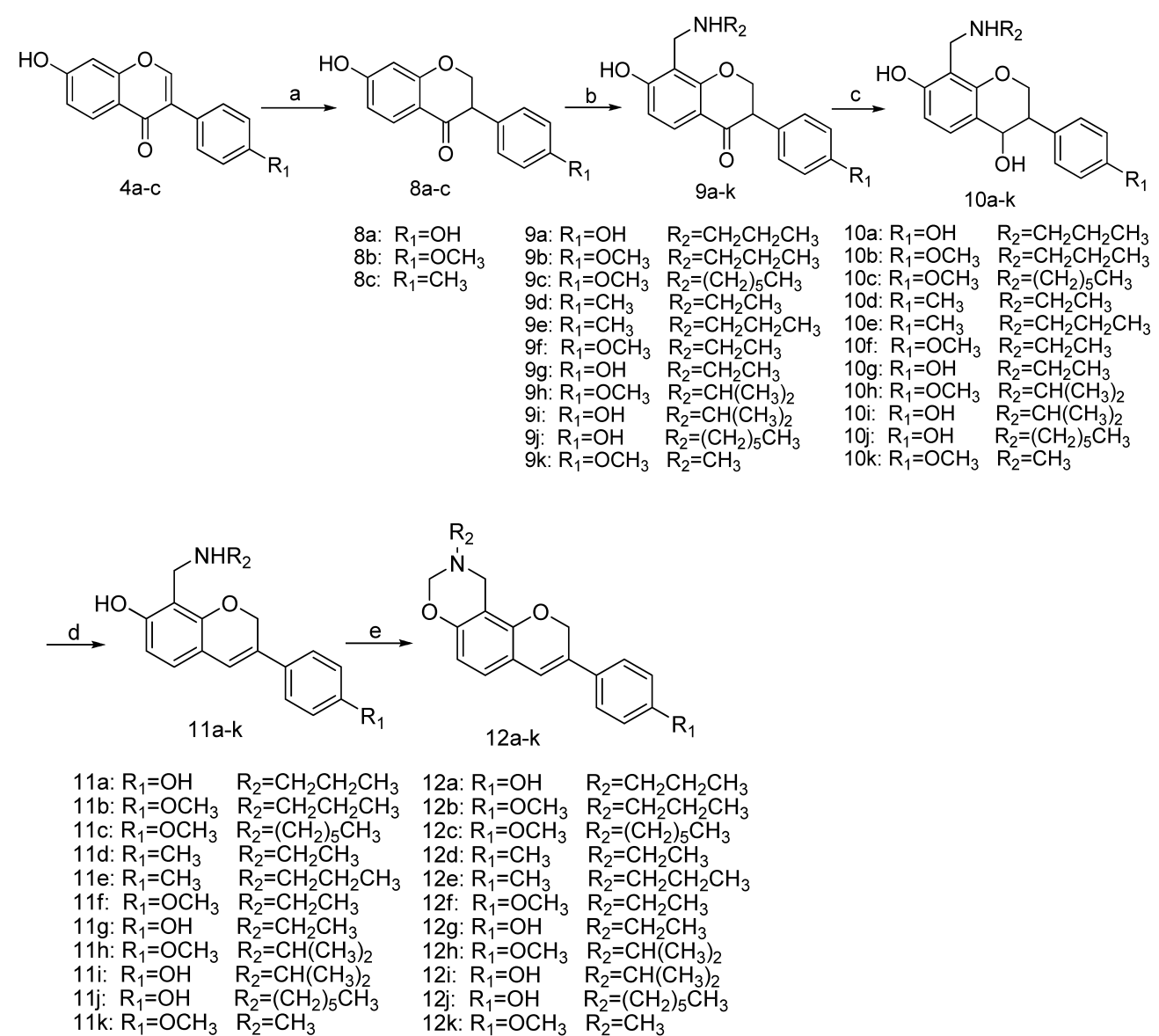

Reaction conditions: (a) $10 \% \mathrm{Pd} / \mathrm{C}, \mathrm{HCOONH}_{4}, \mathrm{CH}_{3} \mathrm{OH}, 70^{\circ}$ (b) $\mathrm{R}_{2} \mathrm{NH}_{2}, 37 \% \mathrm{HCHO}, 1,4-d i o x a n e, 45-70^{\circ} \mathrm{C}$; (c) $\mathrm{NaBH}_{4}, \mathrm{CH}_{3} \mathrm{OH}$; (d) $\mathrm{EtOH}, \mathrm{HCl} \cdot \mathrm{EtOH}$; (e) $(\mathrm{HCHO})_{n}$, $\mathrm{KOH}, \mathrm{CH}_{3} \mathrm{OH}$

Chart 2. The Synthesis of Oxazinyl Isoflavonoid Compounds 12a-k

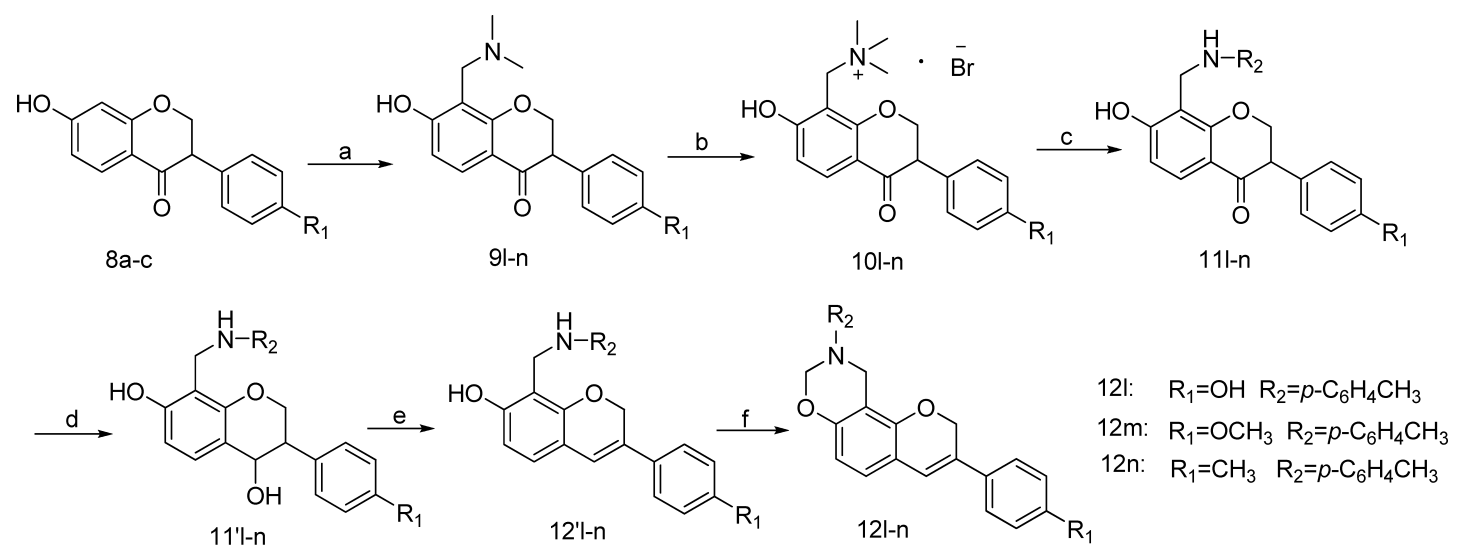

Reaction conditions: (a) $\left(\mathrm{CH}_{3}\right)_{2} \mathrm{NH}, 37 \% \mathrm{HCHO}, 1,4$-dioxane, $45-70^{\circ} \mathrm{C}$; (b) $\mathrm{CH}_{3} \mathrm{COCH}_{3}, \mathrm{CH}_{3} \mathrm{Br}$, r.t.; (c) $\mathrm{ArNH}_{2}, \mathrm{CH}_{3} \mathrm{COOH} \mathrm{EtOH}, 80^{\circ}$; (d) $\mathrm{NaBH}$, $\mathrm{CH} 3 \mathrm{OH}$; (e) EtOH, $\mathrm{HCl} \cdot \mathrm{EtOH}$; (f) (HCHO) $)_{n}, \mathrm{KOH}, \mathrm{CH}_{3} \mathrm{OH}$

Chart 3. The Synthetic Route of Target Compounds 12I-n

compounds $\mathbf{4 a}-\mathbf{c}$ with a primary amine and formaldehyde in 1,4-dioxane via a Mannich reaction ${ }^{7)}$ afforded compounds 5ag, which were converted into their corresponding isoflavans $\mathbf{6 a}-\mathbf{g}$ via transfer hydrogenations with ammonium formate, as the hydrogen donator, in acetic acid. By reacting compounds $\mathbf{6} \mathbf{a}-\mathbf{g}$ with paraformaldehyde in the presence of potassium hydroxide, compounds of type I, the chromano[8,7-e][1,3]oxazine derivatives $\mathbf{7 a}-\mathbf{g}$, were obtained, respectively (Chart 1).

The reductions of intermediates $4 \mathbf{a}-\mathbf{c}$ were performed via transfer hydrogenations in methanol to obtain isoflavanones $\mathbf{8 a}-\mathbf{c},{ }^{8)}$ which were treated with a primary amine and formaldehyde to obtain the Mannich products 9a-k. Next, reduction of $\mathbf{9 a}-\mathbf{k}$ with $\mathrm{NaBH}_{4}$ in methanol conveniently afforded isolavan-4-ols $\mathbf{1 0 a}-\mathbf{k}$, which were dehydrolyzed by $\mathrm{HCl}$ / EtOH in ethanol at room temperature to yield compounds 11a-k. Finally, treating $11 \mathbf{a}-\mathbf{k}$ with paraformaldehyde and potassium hydroxide gave compounds of type II, the desired chromeno[8,7-e][1,3] oxazine derivatives 12a-k (Chart 2). 
<smiles>[R]NCc1c(O)ccc2c1OCC(c1ccc([R])cc1)C2=O</smiles>

9a: $\mathrm{R}_{1}=\mathrm{OH} \quad \mathrm{R}_{2}=\mathrm{CH}_{2} \mathrm{CH}_{2} \mathrm{CH}_{3}$ 9b: $\mathrm{R}_{1}=\mathrm{OCH}_{3} \quad \mathrm{R}_{2}=\mathrm{CH}_{2} \mathrm{CH}_{2} \mathrm{CH}_{3}$ 9c: $\mathrm{R}_{1}=\mathrm{OCH}_{3} \quad \mathrm{R}_{2}=\left(\mathrm{CH}_{2}\right)_{5} \mathrm{CH}_{3}$ 9d: $\mathrm{R}_{1}=\mathrm{CH}_{3} \quad \mathrm{R}_{2}=\mathrm{CH}_{2} \mathrm{CH}_{3}$ 9e: $\mathrm{R}_{1}=\mathrm{CH}_{3} \quad \mathrm{R}_{2}=\mathrm{CH}_{2} \mathrm{CH}_{2} \mathrm{CH}_{3}$

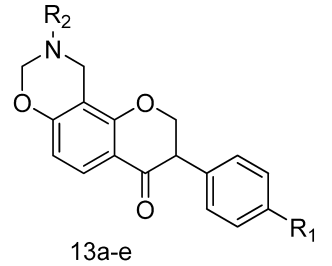

13a: $\mathrm{R}_{1}=\mathrm{OH} \quad \mathrm{R}_{2}=\mathrm{CH}_{2} \mathrm{CH}_{2} \mathrm{CH}_{3}$ 13b: $\mathrm{R}_{1}=\mathrm{OCH}_{3} \quad \mathrm{R}_{2}=\mathrm{CH}_{2} \mathrm{CH}_{2} \mathrm{CH}_{3}$ 13c: $\mathrm{R}_{1}=\mathrm{OCH}_{3} \quad \mathrm{R}_{2}=\left(\mathrm{CH}_{2}\right)_{5} \mathrm{CH}_{3}$ 13d: $\mathrm{R}_{1}=\mathrm{CH}_{3} \quad \mathrm{R}_{2}=\mathrm{CH}_{2} \mathrm{CH}_{3}$ 13e: $\mathrm{R}_{1}=\mathrm{CH}_{3} \quad \mathrm{R}_{2}=\mathrm{CH}_{2} \mathrm{CH}_{2} \mathrm{CH}_{3}$

Reaction conditions: (a) $(\mathrm{HCHO})_{n}, \mathrm{KOH}, \mathrm{CH}_{3} \mathrm{OH}$

Chart 4. The Synthesis of Oxazinyl Isoflavonoid Compounds 13a-e

Unfortunately, the chromeno[8,7-e][1,3] oxazine derivatives 12l-n, bearing the aryl group at the N-9 position, could not be prepared according to the procedure described above. The main reason is that $\mathbf{1 1}-\mathbf{n}$ can't be prepared directly by Mannich Reaction. As shown in Chart 3, isolavanones 8a-c were instead treated with dimethylamine and formaldehyde to generate Mannich bases 9l-n, which were subsequently quaternized in acetone with $\mathrm{CH}_{3} \mathrm{Br}$ at room temperature to achieve quaternary ammonium salts 101-n. Next, compounds 111-n were prepared by reacting 10I-n with an arylamine in ethanol and acetic acid as the catalyst. Reducing the carbonyl groups at the C-4 positions of 111-n, followed by dehydration and cyclization, provided target compounds 12l-n (Chart 3).

Compounds of type III, the chromeno[8,7-e][1,3]oxazin4-ones $\mathbf{1 3 a}-\mathbf{e}$, were prepared by directly reacting $9 \mathbf{a}-\mathbf{e}$ with paraformaldehyde and potassium hydroxide in methanol while in an ice bath (Chart 4).

Compound 8a treated with dimethyl sulfate in the presence of sodium bicarbonate provided selectively methylated compound 14. Treatment of $\mathbf{1 4}$ with $\mathrm{KBH}_{4}$ instead of $\mathrm{NaBH}_{4}$ in methanol provided 7-methoxy-4'-hydroxyisoflavan-4-ol (15), which was dehydrolyzed to compound 16. The reaction time had been shortened and the yields had been improved by using $\mathrm{KBH}_{4}$ instead of $\mathrm{NaBH}_{4}$ on the basis of the following experimental result. Compound $\mathbf{1 6}$ underwent a Mannich reaction, followed by condensation with paraformaldehyde to give compounds of type IV, 6-(chromen-3-yl)-benzo[e][1,3]oxazine 18a-d (Chart 5).

\section{Results and Discussion}

Thirty compounds were synthesized in the current study, and we utilized the 3-(4,5-dimethylthiazol-2-yl)-2,5-diphenyltetrazolium bromide (MTT) colorimetric assay to determine their $\mathrm{IC}_{50}$ in vitro growth inhibitory values in a human ovarian cancer cell line (SKOV-3) and human prostate cancer cell line (DU-145). Additionally, the Trypan blue dye exclusion assay was employed to evaluate the growth inhibitory effects of the tested compounds against a human leukemic cell line (HL60). Cisplatin and parental compound phenoxodiol were both used as positive controls. The ability of these new analogs to inhibit the growth of cancer cell lines is summarized in Table 1.

In general, with modifications to the A ring, both isoflavane derivatives $7 \mathbf{a}-\mathbf{g}$ and isoflavene derivatives $\mathbf{1 2} \mathbf{a}-\mathbf{k}$ showed increased activities compared with their parent compound, phenoxodiol. Compounds $\mathbf{7 f}, \mathbf{1 2 h}$ and $\mathbf{1 2} \mathbf{i}$ showed the best activities with $\mathrm{IC}_{50}$ values in the micromolar range $(1-10 \mu \mathrm{M})$, which may suggest that the increase in the steric hindrance of the aliphatic alkyl substituent on the N-position of the oxazinyl ring is favorable for activity. This finding was further confirmed by $7 \mathbf{c}$, which bore an $n$-hexyl group on the oxazinyl ring. The fact that compounds $\mathbf{1 2 d}$ and $\mathbf{1 2 e}$ diminished the activity revealed that the presence of a hydroxy or methoxy group on the para-position of the $\mathrm{C}$ ring was essential for optimum biological activity. This finding is consistent with the author's previous hypothesis.

The $N$-phenyl substituted isoflavene derivatives 12I-n showed remarkably decreased activities, while compound 12n almost lost activity completely $(>100 \mu \mathrm{M})$, which may imply that an aryl substitution on the oxazinyl ring is not well tolerated.

Isoflavanone derivatives 13a-e were generally inactive, while $\mathbf{1 3 b}$ and $13 \mathbf{e}$ had the lowest activities $\left(\mathrm{IC}_{50}>100 \mu \mathrm{M}\right)$. These results demonstrated that the structural skeleton of isoflavanone had negative effects.

Compounds 18a-d with modifications on the $\mathrm{C}$ ring exhibited comparable activities to phenoxodiol but were less potent than $12 \mathbf{a}-\mathbf{k}$. These two types of compounds were of the same structural skeleton, but the positions of their oxazinyl ring were different, suggesting that integrating the oxazinyl functionality with the A ring of isoflavene is better favored. Of compounds 18a-d, 18d, whose oxazinyl ring was substituted<smiles>COc1ccc2c(c1)OCC(c1ccc(O)cc1)C2O</smiles>

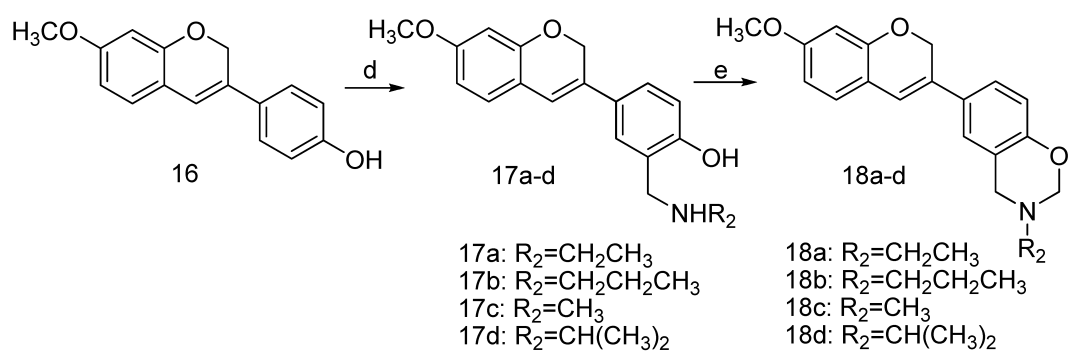

Reaction conditions: (a) $\left(\mathrm{CH}_{3}\right)_{2} \mathrm{SO}_{4}, \mathrm{NaHCO}_{3},\left(\mathrm{CH}_{3}\right)_{2} \mathrm{CO}$; (b) $\mathrm{KBH}_{4}, \mathrm{CH}_{3} \mathrm{OH}$; (c) EtOH, $\mathrm{HCl} \cdot \mathrm{EtOH}$; (d) $\mathrm{R}_{2} \mathrm{NH}_{2}, 37 \% \mathrm{HCHO}$, acetic acid, $1,4-\mathrm{dioxane}, 45-70^{\circ} \mathrm{C}$; (e) $(\mathrm{HCHO})_{n}, \mathrm{KOH}, \mathrm{CH}_{3} \mathrm{OH}$

Chart 5. The synthesis of Oxazinyl Isoflavonoid Compounds $\mathbf{1 8 a}-\mathbf{d}$ 
by an isopropyl group, displayed better potency than the other three compounds. This result was consistent with those we observed in compounds $\mathbf{1 2 a}-\mathbf{k}$.

\section{Conclusions}

In this study, a series of novel isoflavoids containing protected phenolic groups with oxazinyl moieties was synthesized, and each compound was evaluated for its in vitro anti-tumor activities. These compounds showed increased stabilities compared to the parental compound, phenoxodiol. Additionally, the oxazinyl isoflavane and oxazinyl isoflavene derivatives exhibited potent growth inhibitory activities against the SKOV-3, DU-145 and HL-60 cell lines. Specifically, compound $7 \mathbf{f}$ showed the most potent inhibition activities with $\mathrm{IC}_{50}$ values of $0.763,8.132$ and $9.113 \mu \mathrm{mol}$, respectively. This compound was followed by compound $\mathbf{1 2 h}$, whose $\mathrm{IC}_{50}$ values were $3.04,7.483$ and $9.101 \mu \mathrm{mol}$, respectively. We observed that both of the above compounds had aliphatic alkyl groups with steric hindrances at the $\mathrm{N}$-atoms of their oxazinyl rings. Overall, the information from this study may be helpful for the design and synthesis of isoflavoid derivatives with stronger activities and better stabilities.

\section{Experimental}

All the reagents and solvents were purchased from common commercial suppliers and used without further purification. Nuclear magnetic resonance spectra were recorded in $\mathrm{CDCl}_{3}$ or $d$-DMSO solutions on a Bruker AX 300 spectrometer. Chemical shifts were reported in $\delta$ (ppm) relative to the internal standard of tetramethylsilane (TMS), and $J$ values were reported in Hz. Mass spectra were taken on an Agilent 1100 LC-MS electrospray/ion trap instrument in positive and negative ion modes. Compounds $\mathbf{3 a}-\mathbf{c}, \mathbf{4 a}-\mathbf{c}$, and $\mathbf{8 a}-\mathbf{c}$ were synthesized according to the literature. ${ }^{6,8,9)}$.

3-(4- $R_{1}$-Phenyl)-9- $R_{2}-2,3,4,8,9,10$-hexahydrochromeno$[\mathbf{8 , 7}-\boldsymbol{e}][\mathbf{1 , 3}]$ oxazines $(\mathbf{7 a}-\mathbf{g})$ A primary amine $(20.7 \mathrm{mmol})$ and a $37 \%$ formaldehyde solution $(1.4 \mathrm{~g}, 16.6 \mathrm{mmol})$ were dissolved in 1,4-dioxane $(1 \mathrm{~mL})$ at $45^{\circ} \mathrm{C}$ and stirred for $15 \mathrm{~min}$, and then the resulting mixture was added to a solution mixture of $\mathbf{4 a}-\mathbf{c}(13.8 \mathrm{mmol})$ in 1,4-dioxane $(35 \mathrm{~mL})$. The mixture was heated at $70^{\circ} \mathrm{C}$ for $2-4 \mathrm{~h}$ and then concentrated in vacuo. The residue was collected under suction filtration and dried to afford compounds $\mathbf{5 a}-\mathbf{g}$.

Next, ammonium formate $(3.97 \mathrm{~g}, 63 \mathrm{mmol})$ and $10 \% \mathrm{Pd} / \mathrm{C}$ $(1.5 \mathrm{~g})$, followed by solids $\mathbf{5 a}-\mathbf{g}(10.0 \mathrm{mmol})$, were added to acetic acid $(45 \mathrm{~mL})$. The suspension was heated to $110^{\circ} \mathrm{C}$ for $45 \mathrm{~min}$. After filtering, the filtrate was concentrated to remove a majority of the solvent, and subsequently poured into icecold water $(100 \mathrm{~mL})$ and extracted with chloroform $(2 \times 60 \mathrm{~mL})$. The collected organic layers were dried over $\mathrm{Na}_{2} \mathrm{SO}_{4}$, and the solvent was removed under reduced pressure to give $\mathbf{6 a}-\mathbf{g}$.

Finally, compounds $\mathbf{6 a}-\mathbf{g}(4.0 \mathrm{mmol})$ were dissolved in methanol $(2.0 \mathrm{~mL})$, and the methanolic solution was added to paraformaldehyde $(0.36 \mathrm{~g}, 12.0 \mathrm{mmol})$ and potassium hydroxide $(0.02 \mathrm{~g}, 0.4 \mathrm{mmol})$, which were stirred at room temperature. After stirring, a white precipitate was collected to afford compounds $7 \mathbf{a}-\mathbf{g}$.

7a: Yield 56\%; MS $[\mathrm{M}+\mathrm{H}]^{+} \quad(\mathrm{m} / \mathrm{z}): 312.1 ;{ }^{1} \mathrm{H}-\mathrm{NMR}$ $\left(300 \mathrm{MHz}, \mathrm{CDCl}_{3}\right) \delta: 1.20\left(3 \mathrm{H}, \mathrm{t}, J=7.2 \mathrm{~Hz}, \mathrm{CH}_{3}\right), 2.81(2 \mathrm{H}$, q, $\left.J=7.2 \mathrm{~Hz}, \mathrm{NCH}_{2} \mathrm{CH}_{3}\right), 2.91\left(2 \mathrm{H}, \mathrm{m}, \mathrm{PhCH}_{2} \mathrm{CH}\right), 3.11(1 \mathrm{H}$, $\left.\mathrm{m}, \mathrm{CH}_{2} \mathrm{CHCH}_{2} \mathrm{O}\right), 3.94\left(2 \mathrm{H}, \mathrm{s}, \mathrm{PhCH}_{2} \mathrm{~N}\right), 3.94-4.30(2 \mathrm{H}, \mathrm{m}$,
$\left.\mathrm{OCH}_{2} \mathrm{CH}\right), 4.83\left(2 \mathrm{H}, \mathrm{s}, \mathrm{OCH}_{2} \mathrm{~N}\right), 6.38(1 \mathrm{H}, \mathrm{d}, J=8.4 \mathrm{~Hz}, \mathrm{H} 6)$, $6.84(1 \mathrm{H}, \mathrm{d}, J=8.4 \mathrm{~Hz}, \mathrm{H} 5), 6.80\left(2 \mathrm{H}, \mathrm{d}, J=8.4 \mathrm{~Hz}, \mathrm{H} 3^{\prime}, \mathrm{H} 5^{\prime}\right)$, 7.09 (2H, d, $\left.J=8.4 \mathrm{~Hz}, \mathrm{H} 2^{\prime}, \mathrm{H6}^{\prime}\right)$.

7b: Yield $62 \% ; \quad \mathrm{MS}[\mathrm{M}+\mathrm{H}]^{+}(\mathrm{m} / \mathrm{z}): 326.2 ;{ }^{1} \mathrm{H}-\mathrm{NMR}$ $\left(300 \mathrm{MHz}, \mathrm{CDCl}_{3}\right) \delta: 0.93\left(3 \mathrm{H}, \mathrm{t}, J=7.5 \mathrm{~Hz}, \mathrm{CH}_{3}\right), 1.61(2 \mathrm{H}$, $\left.\mathrm{m}, \mathrm{CH}_{2} \mathrm{CH}_{3}\right), 2.72\left(2 \mathrm{H}, \mathrm{t}, J=7.2 \mathrm{~Hz}, \mathrm{NCH}_{2} \mathrm{CH}_{2}\right), 2.94(2 \mathrm{H}$, $\left.\mathrm{m}, \mathrm{PhCH}_{2} \mathrm{CH}\right), 3.13\left(1 \mathrm{H}, \mathrm{m}, \mathrm{CH}_{2} \mathrm{CHCH}_{2} \mathrm{O}\right), 3.93(2 \mathrm{H}, \mathrm{s}$, $\left.\mathrm{PhCH}_{2} \mathrm{~N}\right), 3.93-4.30\left(2 \mathrm{H}, \mathrm{m}, \mathrm{OCH}_{2} \mathrm{CH}\right), 4.82\left(2 \mathrm{H}, \mathrm{s}, \mathrm{OCH}_{2} \mathrm{~N}\right)$, $6.38(1 \mathrm{H}, \mathrm{d}, J=8.4 \mathrm{~Hz}, \mathrm{H} 6), 6.84(1 \mathrm{H}, \mathrm{d}, J=8.4 \mathrm{~Hz}, \mathrm{H} 5), 6.82$ ( $\left.2 \mathrm{H}, \mathrm{d}, J=8.4 \mathrm{~Hz}, \mathrm{H} 3^{\prime}, \mathrm{H} 5^{\prime}\right), 7.10$ (2H, d, $\left.J=8.4 \mathrm{~Hz}, \mathrm{H} 2^{\prime}, \mathrm{H6}^{\prime}\right)$.

7c: Yield 58\%; $\mathrm{MS}[\mathrm{M}+\mathrm{H}]^{+} \quad(\mathrm{m} / \mathrm{z}): \quad 368.1 ;{ }^{1} \mathrm{H}-\mathrm{NMR}$ $\left(300 \mathrm{MHz}, \mathrm{CDCl}_{3}\right) \delta: 0.88\left(3 \mathrm{H}, \mathrm{t}, J=6.6 \mathrm{~Hz}, \mathrm{CH}_{3}\right), 1.30-1.56$ $\left(8 \mathrm{H}, \mathrm{m}, \mathrm{CH}_{3}\left(\mathrm{CH}_{2}\right)_{4}\right), 2.75\left(2 \mathrm{H}, \mathrm{t}, J=7.5 \mathrm{~Hz}, \mathrm{NCH}_{2} \mathrm{CH}_{2}\right), 2.91$ $\left(2 \mathrm{H}, \mathrm{m}, \mathrm{PhCH}_{2} \mathrm{CH}\right), 3.12\left(1 \mathrm{H}, \mathrm{m}, \mathrm{CH}_{2} \mathrm{CHCH}_{2} \mathrm{O}\right), 3.91(2 \mathrm{H}, \mathrm{s}$, $\left.\mathrm{PhCH}_{2} \mathrm{~N}\right), 3.91-4.31\left(2 \mathrm{H}, \mathrm{m}, \mathrm{OCH}_{2} \mathrm{CH}\right), 4.81\left(2 \mathrm{H}, \mathrm{s}, \mathrm{OCH}_{2} \mathrm{~N}\right)$, $6.37(1 \mathrm{H}, \mathrm{d}, J=8.4 \mathrm{~Hz}, \mathrm{H} 6), 6.85(1 \mathrm{H}, \mathrm{d}, J=8.4 \mathrm{~Hz}, \mathrm{H} 5), 6.81$ ( $\left.2 \mathrm{H}, \mathrm{d}, J=7.8 \mathrm{~Hz}, \mathrm{H} 3^{\prime}, \mathrm{H} 5^{\prime}\right), 7.10\left(2 \mathrm{H}, \mathrm{d}, J=7.8 \mathrm{~Hz}, \mathrm{H} 2^{\prime}, \mathrm{H}^{\prime}\right)$.

7d: Yield 72\%; MS $[\mathrm{M}+\mathrm{H}]^{+}(\mathrm{m} / \mathrm{z}): 324.3 ;{ }^{1} \mathrm{H}-\mathrm{NMR}$ $\left(300 \mathrm{MHz}, \mathrm{CDCl}_{3}\right) \quad \delta: 0.93\left(3 \mathrm{H}, \mathrm{t}, J=7.2 \mathrm{~Hz}, \mathrm{CH}_{3}\right), 1.59$ $\left(2 \mathrm{H}, \mathrm{m}, \mathrm{CH}_{2} \mathrm{CH}_{3}\right), 2.34\left(3 \mathrm{H}, \mathrm{s}, \mathrm{PhCH}_{3}\right), 2.70(2 \mathrm{H}, \mathrm{t}$, $\left.J=7.5 \mathrm{~Hz}, \mathrm{NCH}_{2} \mathrm{CH}_{2}\right), 2.91\left(2 \mathrm{H}, \mathrm{m}, \mathrm{PhCH}_{2} \mathrm{CH}\right), 3.14(1 \mathrm{H}$, m, $\left.\mathrm{CH}_{2} \mathrm{CHCH}_{2} \mathrm{O}\right), 3.92\left(2 \mathrm{H}, \mathrm{s}, \mathrm{PhCH}_{2} \mathrm{~N}\right), 3.97-4.34(2 \mathrm{H}, \mathrm{m}$, $\left.\mathrm{OCH}_{2} \mathrm{CH}\right), 4.81\left(2 \mathrm{H}, \mathrm{s}, \mathrm{OCH}_{2} \mathrm{~N}\right), 6.37(1 \mathrm{H}, \mathrm{d}, J=8.4 \mathrm{~Hz}, \mathrm{H} 6)$, $6.84(1 \mathrm{H}, \mathrm{d}, J=8.1 \mathrm{~Hz}, \mathrm{H} 5), 7.12\left(2 \mathrm{H}, \mathrm{d}, J=8.4 \mathrm{~Hz}, \mathrm{H} 3^{\prime}, \mathrm{H}^{\prime}\right)$, $7.17\left(2 \mathrm{H}, \mathrm{d}, J=8.4 \mathrm{~Hz}, \mathrm{H} 2^{\prime}, \mathrm{H} 6^{\prime}\right)$.

7e: Yield 76\%; MS $[\mathrm{M}+\mathrm{H}]^{+} \quad(\mathrm{m} / \mathrm{z}): \quad 310.1 ; \quad{ }^{1} \mathrm{H}-\mathrm{NMR}$ $\left(300 \mathrm{MHz}, \mathrm{CDCl}_{3}\right) \delta: 1.19\left(3 \mathrm{H}, \mathrm{t}, J=7.2 \mathrm{~Hz}, \mathrm{CH}_{3}\right), 2.35(3 \mathrm{H}$, $\left.\mathrm{s}, \mathrm{PhCH}_{3}\right), 2.80\left(2 \mathrm{H}, \mathrm{q}, J=7.2 \mathrm{~Hz}, \mathrm{NCH}_{2} \mathrm{CH}_{3}\right), 2.94(2 \mathrm{H}$, $\left.\mathrm{m}, \mathrm{PhCH}_{2} \mathrm{CH}\right), 3.15\left(1 \mathrm{H}, \mathrm{m}, \mathrm{CH}_{2} \mathrm{CHCH}_{2} \mathrm{O}\right), 3.93(2 \mathrm{H}, \mathrm{s}$, $\left.\mathrm{PhCH}_{2} \mathrm{~N}\right), 3.98-4.33\left(2 \mathrm{H}, \mathrm{m}, \mathrm{OCH}_{2} \mathrm{CH}\right), 4.83\left(2 \mathrm{H}, \mathrm{s}, \mathrm{OCH}_{2} \mathrm{~N}\right)$, $6.37(1 \mathrm{H}, \mathrm{d}, J=8.4 \mathrm{~Hz}, \mathrm{H} 6), 6.85(1 \mathrm{H}, \mathrm{d}, J=8.4 \mathrm{~Hz}, \mathrm{H} 5), 7.13$ (2H, d, $\left.J=8.4 \mathrm{~Hz}, \mathrm{H} 3^{\prime}, \mathrm{H}^{\prime}\right), 7.17$ (2H, d, $\left.J=8.1 \mathrm{~Hz}, \mathrm{H} 2^{\prime}, \mathrm{H}^{\prime}\right)$.

7f: Yield 70\%; MS $[\mathrm{M}+\mathrm{H}]^{+}(\mathrm{m} / \mathrm{z}): 354.1 ;{ }^{1} \mathrm{H}-\mathrm{NMR}$ $\left(300 \mathrm{MHz}, \mathrm{CDCl}_{3}\right) \delta: 1.22\left(9 \mathrm{H}, \mathrm{s}, \mathrm{C}\left(\mathrm{CH}_{3}\right)_{3}\right), 2.92(2 \mathrm{H}, \mathrm{m}$, $\left.\mathrm{PhCH}_{2} \mathrm{CH}\right), 3.16\left(1 \mathrm{H}, \mathrm{m}, \mathrm{CH}_{2} \mathrm{CHCH}_{2} \mathrm{O}\right), 3.81\left(3 \mathrm{H}, \mathrm{s}, \mathrm{PhOCH}_{3}\right)$, $4.00\left(2 \mathrm{H}, \mathrm{s}, \mathrm{PhCH}_{2} \mathrm{~N}\right), 3.95-4.34\left(2 \mathrm{H}, \mathrm{m}, \mathrm{OCH}_{2} \mathrm{CH}\right), 4.93(2 \mathrm{H}$, $\left.\mathrm{s}, \mathrm{OCH}_{2} \mathrm{~N}\right), 6.35(1 \mathrm{H}, \mathrm{d}, J=8.1 \mathrm{~Hz}, \mathrm{H} 6), 6.82(1 \mathrm{H}, \mathrm{d}, J=8.4 \mathrm{~Hz}$, H5), 6.89 (2H, d, J=8.7 Hz, H3', H5'), $7.17(2 \mathrm{H}, \mathrm{d}, J=8.7 \mathrm{~Hz}$, $\left.\mathrm{H} 2^{\prime}, \mathrm{H} 6^{\prime}\right)$.

7g: Yield 75\%; MS $[\mathrm{M}+\mathrm{H}]^{+} \quad(\mathrm{m} / \mathrm{z}): 325.9 ;{ }^{1} \mathrm{H}-\mathrm{NMR}$ $\left(300 \mathrm{MHz}, \mathrm{CDCl}_{3}\right) \delta: 0.93\left(3 \mathrm{H}, \mathrm{t}, J=7.5 \mathrm{~Hz}, \mathrm{CH}_{3}\right), 1.60(2 \mathrm{H}$, $\left.\mathrm{m}, \mathrm{CH}_{2} \mathrm{CH}_{3}\right), 2.71\left(2 \mathrm{H}, \mathrm{t}, J=7.5 \mathrm{~Hz}, \mathrm{NCH}_{2} \mathrm{CH}_{2}\right), 2.93(2 \mathrm{H}, \mathrm{m}$, $\left.\mathrm{PhCH}_{2} \mathrm{CH}\right), 3.14\left(1 \mathrm{H}, \mathrm{m}, \mathrm{CH}_{2} \mathrm{CHCH}_{2} \mathrm{O}\right), 3.81\left(3 \mathrm{H}, \mathrm{s}, \mathrm{PhOCH}_{3}\right)$, $3.91\left(2 \mathrm{H}, \mathrm{s}, \mathrm{PhCH}_{2} \mathrm{~N}\right), 3.95-4.32\left(2 \mathrm{H}, \mathrm{m}, \mathrm{OCH}_{2} \mathrm{CH}\right), 4.81(2 \mathrm{H}$, $\left.\mathrm{s}, \mathrm{OCH}_{2} \mathrm{~N}\right), 6.37(1 \mathrm{H}, \mathrm{d}, J=8.1 \mathrm{~Hz}, \mathrm{H} 6), 6.84(1 \mathrm{H}, \mathrm{d}, J=8.4 \mathrm{~Hz}$, H5), 6.89 (2H, d, $\left.J=8.7 \mathrm{~Hz}, \mathrm{H} 3^{\prime}, \mathrm{H}^{\prime}\right), 7.16(2 \mathrm{H}, \mathrm{d}, J=8.7 \mathrm{~Hz}$, $\left.\mathrm{H} 2^{\prime}, \mathrm{H} 6^{\prime}\right)$.

3-(4-R1-Phenyl)-9-R $-2,8,9,10$-tetrahydrochromeno[8,7e] $[1,3]$ oxazines $(12 \mathbf{a}-\mathbf{n})$ Compounds $9 \mathbf{a}-\mathbf{k}$ were obtained using compounds $\mathbf{8 a}-\mathbf{c}$ as the starting materials in the Mannich reaction described in Section "Synthesis". Next, a solid mixture of compounds $\mathbf{9 a}-\mathbf{k}(8.0 \mathrm{mmol})$ was dissolved in methanol $(160 \mathrm{~mL})$ and treated with $\mathrm{NaBH}_{4}(3.1 \mathrm{~g}, 80 \mathrm{mmol})$ for $48 \mathrm{~h}$ at room temperature. The reaction was quenched with a saturated ammonium chloride solution $(12.5 \mathrm{~mL})$ and then was poured into ice water $(500 \mathrm{~mL})$. The solution was extracted with ethyl acetate $(2 \times 100 \mathrm{~mL})$, and the ethyl acetate layers were dried with $\mathrm{Na}_{2} \mathrm{SO}_{4}$ and concentrated under reduced pressure to give solids $\mathbf{1 0 a}-\mathbf{k}$. Compounds $\mathbf{1 0 a}-\mathbf{k}(3.0 \mathrm{mmol})$ were dehydrated by treating with $\mathrm{HCl} / \mathrm{EtOH}(5.0 \mathrm{~mL}, 4.5 \mathrm{mmol})$, and thus, a faint yellow precipitate, containing compounds 
11a-k, was collected under suction filtration. Title compounds $\mathbf{1 2 a}-\mathbf{k}$ were prepared by reacting $\mathbf{1 1 a}-\mathbf{k}(1.5 \mathrm{mmol})$ with paraformaldehyde $(0.14 \mathrm{~g}, 4.5 \mathrm{mmol})$ in the presence of potassium hydroxide at room temperature in methanol.

12a: Yield $87 \%$; MS $[\mathrm{M}+\mathrm{H}]^{+}(\mathrm{m} / \mathrm{z})$ : 323.9; ${ }^{1} \mathrm{H}-\mathrm{NMR}$ $\left(300 \mathrm{MHz}, \mathrm{CDCl}_{3}\right) \delta: 0.94\left(3 \mathrm{H}, \mathrm{t}, J=7.2 \mathrm{~Hz}, \mathrm{CH}_{3}\right), 1.63(2 \mathrm{H}$, $\left.\mathrm{m}, \mathrm{CH}_{2} \mathrm{CH}_{3}\right), 2.72\left(2 \mathrm{H}, \mathrm{t}, J=7.4 \mathrm{~Hz}, \mathrm{NCH}_{2} \mathrm{CH}_{2}\right), 3.96(2 \mathrm{H}, \mathrm{s}$, $\left.\mathrm{PhCH}_{2} \mathrm{~N}\right), 4.84\left(2 \mathrm{H}, \mathrm{s}, \mathrm{OCH}_{2} \mathrm{C}\right), 5.10\left(2 \mathrm{H}, \mathrm{s}, \mathrm{OCH}_{2} \mathrm{~N}\right), 6.37$ $(1 \mathrm{H}, \mathrm{d}, J=8.1 \mathrm{~Hz}, \mathrm{H} 6), 6.63(1 \mathrm{H}, \mathrm{s}, \mathrm{PhCH}=\mathrm{C}), 6.84(2 \mathrm{H}, \mathrm{d}$, $\left.J=8.7 \mathrm{~Hz}, \mathrm{H} 3^{\prime}, \mathrm{H}^{\prime}\right), 6.85(1 \mathrm{H}, \mathrm{d}, J=8.1 \mathrm{~Hz}, \mathrm{H} 5), 7.28(2 \mathrm{H}, \mathrm{d}$, $J=8.7 \mathrm{~Hz}, \mathrm{H} 2^{\prime}, \mathrm{H}^{\prime}$ ).

12b: Yield 89\%; MS $[\mathrm{M}+\mathrm{H}]^{+}(\mathrm{m} / \mathrm{z}): 338.1 ;{ }^{1} \mathrm{H}-\mathrm{NMR}$ $\left(300 \mathrm{MHz}, \mathrm{CDCl}_{3}\right) \delta: 0.94\left(3 \mathrm{H}, \mathrm{t}, J=7.35 \mathrm{~Hz}, \mathrm{CH}_{3}\right), 1.60(2 \mathrm{H}$, $\left.\mathrm{m}, \mathrm{CH}_{2} \mathrm{CH}_{3}\right), 2.71\left(2 \mathrm{H}, \mathrm{t}, J=7.5 \mathrm{~Hz}, \mathrm{NCH}_{2} \mathrm{CH}_{2}\right), 3.83(3 \mathrm{H}$, $\left.\mathrm{s}, \mathrm{PhOCH}_{3}\right), 3.95\left(2 \mathrm{H}, \mathrm{s}, \mathrm{PhCH}_{2} \mathrm{~N}\right), 4.84\left(2 \mathrm{H}, \mathrm{s}, \mathrm{OCH}_{2} \mathrm{C}\right)$, $5.12\left(2 \mathrm{H}, \mathrm{s}, \mathrm{OCH}_{2} \mathrm{~N}\right), 6.37(1 \mathrm{H}, \mathrm{d}, J=8.28 \mathrm{~Hz}, \mathrm{H} 6), 6.65$ $(1 \mathrm{H}, \mathrm{s}, \mathrm{PhCH}=\mathrm{C}), 6.85(1 \mathrm{H}, \mathrm{d}, J=8.31 \mathrm{~Hz}, \mathrm{H} 5), 6.91(2 \mathrm{H}, \mathrm{d}$, $\left.J=8.73 \mathrm{~Hz}, \mathrm{H} 3^{\prime}, \mathrm{H}^{\prime}\right), 7.34\left(2 \mathrm{H}, \mathrm{d}, J=8.73 \mathrm{~Hz}, \mathrm{H} 2^{\prime}, \mathrm{H}^{\prime}\right)$.

12c: Yield 90\%; MS $[\mathrm{M}+\mathrm{H}]^{+}(\mathrm{m} / \mathrm{z}): 380.2 ;{ }^{1} \mathrm{H}-\mathrm{NMR}$ $\left(300 \mathrm{MHz}, \mathrm{CDCl}_{3}\right) \delta: 0.89\left(3 \mathrm{H}, \mathrm{t}, J=6.6 \mathrm{~Hz}, \mathrm{CH}_{3}\right), 1.30-1.56$ $\left(8 \mathrm{H}, \mathrm{m}, \mathrm{CH}_{3}\left(\mathrm{CH}_{2}\right)_{4}\right), 2.73\left(2 \mathrm{H}, \mathrm{t}, J=7.5 \mathrm{~Hz}, \mathrm{NCH}_{2} \mathrm{CH}_{2}\right), 3.83$ $\left(3 \mathrm{H}, \mathrm{s}, \mathrm{PhOCH}_{3}\right), 3.95\left(2 \mathrm{H}, \mathrm{s}, \mathrm{PhCH}_{2} \mathrm{~N}\right), 4.84\left(2 \mathrm{H}, \mathrm{s}, \mathrm{OCH}_{2} \mathrm{C}\right)$, $5.12\left(2 \mathrm{H}, \mathrm{s}, \mathrm{OCH}_{2} \mathrm{~N}\right), 6.37(1 \mathrm{H}, \mathrm{d}, J=8.4 \mathrm{~Hz}, \mathrm{H} 6), 6.65(1 \mathrm{H}, \mathrm{s}$, $\mathrm{PhCH}=\mathrm{C}), 6.86(1 \mathrm{H}, \mathrm{d}, J=8.1 \mathrm{~Hz}, \mathrm{H} 5), 6.92(2 \mathrm{H}, \mathrm{d}, J=9.0 \mathrm{~Hz}$, H3', H5'), 7.34 (2H, d, J=8.8 Hz, H2', H6').

12d: Yield 90\%; MS $[\mathrm{M}+\mathrm{H}]^{+}(\mathrm{m} / \mathrm{z})$ : 308.1; ${ }^{1} \mathrm{H}-\mathrm{NMR}$ $\left(300 \mathrm{MHz}, \mathrm{CDCl}_{3}\right) \delta: 1.19\left(3 \mathrm{H}, \mathrm{t}, J=7.2 \mathrm{~Hz}, \mathrm{CH}_{3}\right), 2.36(3 \mathrm{H}$, $\left.\mathrm{s}, \mathrm{PhCH}_{3}\right), 2.81\left(2 \mathrm{H}, \mathrm{q}, J=6.9 \mathrm{~Hz}, \mathrm{NCH}_{2} \mathrm{CH}_{3}\right), 3.97(2 \mathrm{H}, \mathrm{s}$, $\left.\mathrm{PhCH}_{2} \mathrm{~N}\right), 4.85\left(2 \mathrm{H}, \mathrm{s}, \mathrm{OCH}_{2} \mathrm{C}\right), 5.14\left(2 \mathrm{H}, \mathrm{s}, \mathrm{OCH}_{2} \mathrm{~N}\right), 6.37$ $(1 \mathrm{H}, \mathrm{d}, J=8.4 \mathrm{~Hz}, \mathrm{H} 6), 6.70(1 \mathrm{H}, \mathrm{s}, \mathrm{PhCH}=\mathrm{C}), 6.86(1 \mathrm{H}, \mathrm{d}$, $J=8.4 \mathrm{~Hz}, \mathrm{H} 5), 7.18\left(2 \mathrm{H}, \mathrm{d}, J=8.1 \mathrm{~Hz}, \mathrm{H} 3^{\prime}, \mathrm{H} 5^{\prime}\right), 7.30(2 \mathrm{H}, \mathrm{d}$, $\left.J=7.8 \mathrm{~Hz}, \mathrm{H} 2^{\prime}, \mathrm{H}^{\prime}\right)$.

12e: Yield $89 \%$; MS $[\mathrm{M}+\mathrm{H}]^{+}(\mathrm{m} / \mathrm{z}): 321.9 ; \quad{ }^{1} \mathrm{H}-\mathrm{NMR}$ $\left(300 \mathrm{MHz}, \mathrm{CDCl}_{3}\right) \delta: 0.94\left(3 \mathrm{H}, \mathrm{t}, J=7.2 \mathrm{~Hz}, \mathrm{CH}_{3}\right), 1.61(2 \mathrm{H}$, $\left.\mathrm{m}, \mathrm{CH}_{2} \mathrm{CH}_{3}\right), 2.36\left(3 \mathrm{H}, \mathrm{s}, \mathrm{PhCH}_{3}\right), 2.71(2 \mathrm{H}, \mathrm{q}, J=7.5 \mathrm{~Hz}$, $\left.\mathrm{NCH}_{2} \mathrm{CH}_{2}\right), 3.95\left(2 \mathrm{H}, \mathrm{s}, \mathrm{PhCH}_{2} \mathrm{~N}\right), 4.84\left(2 \mathrm{H}, \mathrm{s}, \mathrm{OCH}_{2} \mathrm{C}\right), 5.13$ $\left(2 \mathrm{H}, \mathrm{s}, \mathrm{OCH}_{2} \mathrm{~N}\right), 6.37(1 \mathrm{H}, \mathrm{d}, J=8.4 \mathrm{~Hz}, \mathrm{H} 6), 6.71(1 \mathrm{H}, \mathrm{s}$, $\mathrm{PhCH}=\mathrm{C}), 6.86(1 \mathrm{H}, \mathrm{d}, J=8.1 \mathrm{~Hz}, \mathrm{H} 5), 7.18(2 \mathrm{H}, \mathrm{d}, J=8.1 \mathrm{~Hz}$, H3', H5'), 7.30 (2H, d, J=8.1 Hz, H2', H6').

12f: Yield $87 \%$; MS $[\mathrm{M}+\mathrm{H}]^{+}(\mathrm{m} / \mathrm{z}): 323.9 ;{ }^{1} \mathrm{H}-\mathrm{NMR}$ $\left(300 \mathrm{MHz}, \mathrm{CDCl}_{3}\right) \delta: 1.19\left(3 \mathrm{H}, \mathrm{t}, J=7.2 \mathrm{~Hz}, \mathrm{CH}_{3}\right), 2.81(2 \mathrm{H}$, q, $\left.J=7.2 \mathrm{~Hz}, \mathrm{NCH}_{2} \mathrm{CH}_{3}\right), 3.83\left(3 \mathrm{H}, \mathrm{s}, \mathrm{PhOCH}_{3}\right), 3.97(2 \mathrm{H}, \mathrm{s}$, $\left.\mathrm{PhCH}_{2} \mathrm{~N}\right), 4.86\left(2 \mathrm{H}, \mathrm{s}, \mathrm{OCH}_{2} \mathrm{C}\right), 5.12\left(2 \mathrm{H}, \mathrm{s}, \mathrm{OCH}_{2} \mathrm{~N}\right), 6.37$ $(1 \mathrm{H}, \mathrm{d}, J=8.4 \mathrm{~Hz}, \mathrm{H} 6), 6.65(1 \mathrm{H}, \mathrm{s}, \mathrm{PhCH}=\mathrm{C}), 6.86(1 \mathrm{H}, \mathrm{d}$, $J=8.4 \mathrm{~Hz}, \mathrm{H} 5), 6.92\left(2 \mathrm{H}, \mathrm{d}, J=9.0 \mathrm{~Hz}, \mathrm{H} 3^{\prime}, \mathrm{H} 5^{\prime}\right), 7.35(2 \mathrm{H}, \mathrm{d}$, $\left.J=8.8 \mathrm{~Hz}, \mathrm{H} 2^{\prime}, \mathrm{H} 6^{\prime}\right)$.

12g: Yield $86 \%$; MS $[\mathrm{M}+\mathrm{H}]^{+}(\mathrm{m} / \mathrm{z})$ : 310.1; ${ }^{1} \mathrm{H}-\mathrm{NMR}$ $\left(300 \mathrm{MHz}, \mathrm{CDCl}_{3}\right) \delta: 1.08\left(3 \mathrm{H}, \mathrm{t}, J=7.2 \mathrm{~Hz}, \mathrm{CH}_{3}\right), 2.68(2 \mathrm{H}$, q, $\left.J=7.2 \mathrm{~Hz}, \mathrm{NCH}_{2} \mathrm{CH}_{3}\right), 3.84\left(2 \mathrm{H}, \mathrm{s}, \mathrm{PhCH}_{2} \mathrm{~N}\right), 4.80(2 \mathrm{H}, \mathrm{s}$, $\left.\mathrm{OCH}_{2} \mathrm{C}\right), 5.10\left(2 \mathrm{H}, \mathrm{s}, \mathrm{OCH}_{2} \mathrm{~N}\right), 6.31(1 \mathrm{H}, \mathrm{d}, J=8.4 \mathrm{~Hz}, \mathrm{H} 6)$, $6.76(1 \mathrm{H}, \mathrm{s}, \mathrm{PhCH}=\mathrm{C}), 6.78\left(2 \mathrm{H}, \mathrm{d}, J=8.7 \mathrm{~Hz}, \mathrm{H} 3^{\prime}, \mathrm{H} 5^{\prime}\right), 6.89$ $(1 \mathrm{H}, \mathrm{d}, J=8.1 \mathrm{~Hz}, \mathrm{H} 5), 7.35\left(2 \mathrm{H}, \mathrm{d}, J=8.7 \mathrm{~Hz}, \mathrm{H} 2^{\prime}, \mathrm{H}^{\prime}\right)$.

12h: Yield 87\%; MS $[\mathrm{M}+\mathrm{H}]^{+}(\mathrm{m} / \mathrm{z}): 338.2 ;{ }^{1} \mathrm{H}-\mathrm{NMR}$ $\left(300 \mathrm{MHz}, \mathrm{CDCl}_{3}\right) \delta: 1.17\left(6 \mathrm{H}, \mathrm{d}, J=6.6 \mathrm{~Hz}, \mathrm{CH}\left(\mathrm{CH}_{3}\right)_{2}\right)$, $3.11\left(\mathrm{H}, \mathrm{m}, \mathrm{NCH}\left(\mathrm{CH}_{3}\right)_{2}\right), 3.83\left(3 \mathrm{H}, \mathrm{s}, \mathrm{PhOCH}_{3}\right), 4.01(2 \mathrm{H}, \mathrm{s}$, $\left.\mathrm{PhCH}_{2} \mathrm{~N}\right), 4.93\left(2 \mathrm{H}, \mathrm{s}, \mathrm{OCH}_{2} \mathrm{C}\right), 5.12\left(2 \mathrm{H}, \mathrm{s}, \mathrm{OCH}_{2} \mathrm{~N}\right), 6.35$ $(1 \mathrm{H}, \mathrm{d}, J=8.25 \mathrm{~Hz}, \mathrm{H} 6), 6.65(1 \mathrm{H}, \mathrm{s}, \mathrm{PhCH}=\mathrm{C}), 6.84(1 \mathrm{H}, \mathrm{d}$, $J=8.27 \mathrm{~Hz}, \mathrm{H} 5), 6.91\left(2 \mathrm{H}, \mathrm{d}, J=8.8 \mathrm{~Hz}, \mathrm{H} 3^{\prime}, \mathrm{H} 5^{\prime}\right), 7.35(2 \mathrm{H}, \mathrm{d}$, $J=8.8 \mathrm{~Hz}, \mathrm{H} 2^{\prime}, \mathrm{H}^{\prime}$ ).

12i: Yield $86 \%$; $\mathrm{MS}[\mathrm{M}+\mathrm{H}]^{+}(\mathrm{m} / \mathrm{z}): 324.2 ;{ }^{1} \mathrm{H}-\mathrm{NMR}$ $\left(300 \mathrm{MHz}, \mathrm{CDCl}_{3}\right) \delta: 1.18\left(6 \mathrm{H}, \mathrm{d}, J=6.4 \mathrm{~Hz}, \mathrm{CH}\left(\mathrm{CH}_{3}\right)_{2}\right), 3.10$ $\left(1 \mathrm{H}, \mathrm{m}, \mathrm{NCH}\left(\mathrm{CH}_{3}\right)_{2}\right), 4.02\left(2 \mathrm{H}, \mathrm{s}, \mathrm{PhCH}_{2} \mathrm{~N}\right), 4.93(2 \mathrm{H}, \mathrm{s}$, $\left.\mathrm{OCH}_{2} \mathrm{C}\right), 5.11\left(2 \mathrm{H}, \mathrm{s}, \mathrm{OCH}_{2} \mathrm{~N}\right), 6.36(1 \mathrm{H}, \mathrm{d}, J=8.1 \mathrm{~Hz}, \mathrm{H} 6)$, $6.63(1 \mathrm{H}, \mathrm{s}, \mathrm{PhCH}=\mathrm{C}), 6.83\left(2 \mathrm{H}, \mathrm{d}, J=8.7 \mathrm{~Hz}, \mathrm{H} 3^{\prime}, \mathrm{H}^{\prime}\right), 6.83$ $(1 \mathrm{H}, \mathrm{d}, J=8.1 \mathrm{~Hz}, \mathrm{H} 5), 7.29\left(2 \mathrm{H}, \mathrm{d}, J=8.7 \mathrm{~Hz}, \mathrm{H} 2^{\prime}, \mathrm{H6}^{\prime}\right)$.

12j: Yield 87\%; MS $[\mathrm{M}+\mathrm{H}]^{+}(\mathrm{m} / \mathrm{z}): 365.8 ;{ }^{1} \mathrm{H}-\mathrm{NMR}$ $\left(300 \mathrm{MHz}, \mathrm{CDCl}_{3}\right) \delta: 0.87\left(3 \mathrm{H}, \mathrm{t}, J=6.6 \mathrm{~Hz}, \mathrm{CH}_{3}\right), 1.28-1.58$ $\left(8 \mathrm{H}, \mathrm{m}, \mathrm{CH}_{3}\left(\mathrm{CH}_{2}\right)_{4}\right), 2.73\left(2 \mathrm{H}, \mathrm{t}, J=7.5 \mathrm{~Hz}, \mathrm{NCH}_{2} \mathrm{CH}_{2}\right), 3.95$ $\left(2 \mathrm{H}, \mathrm{s}, \mathrm{PhCH}_{2} \mathrm{~N}\right), 4.84\left(2 \mathrm{H}, \mathrm{s}, \mathrm{OCH}_{2} \mathrm{C}\right), 5.11\left(2 \mathrm{H}, \mathrm{s}, \mathrm{OCH}_{2} \mathrm{~N}\right)$, $6.37(1 \mathrm{H}, \mathrm{d}, J=8.1 \mathrm{~Hz}, \mathrm{H} 6), 6.64(1 \mathrm{H}, \mathrm{s}, \mathrm{PhCH}=\mathrm{C}), 6.84(2 \mathrm{H}$, d, $\left.J=8.4 \mathrm{~Hz}, \mathrm{H}^{\prime}, \mathrm{H}^{\prime}\right), 6.85(1 \mathrm{H}, \mathrm{d}, J=8.4 \mathrm{~Hz}, \mathrm{H} 5), 7.29(2 \mathrm{H}$, d, $\left.J=8.7 \mathrm{~Hz}, \mathrm{H} 2^{\prime}, \mathrm{H} 6^{\prime}\right)$.

12k: Yield 88\%; MS $[\mathrm{M}+\mathrm{H}]^{+}(\mathrm{m} / \mathrm{z}): 310.2 ;{ }^{1} \mathrm{H}-\mathrm{NMR}$ $\left(300 \mathrm{MHz}, \mathrm{CDCl}_{3}\right) \delta: 2.62\left(3 \mathrm{H}, \mathrm{s}, \mathrm{NCH}_{3}\right), 3.83(3 \mathrm{H}, \mathrm{s}$, $\left.\mathrm{PhOCH}_{3}\right), 3.93\left(2 \mathrm{H}, \mathrm{s}, \mathrm{PhCH}_{2} \mathrm{~N}\right), 4.77\left(2 \mathrm{H}, \mathrm{s}, \mathrm{OCH}_{2} \mathrm{C}\right), 5.12$ $\left(2 \mathrm{H}, \mathrm{s}, \mathrm{OCH}_{2} \mathrm{~N}\right), 6.39(1 \mathrm{H}, \mathrm{d}, J=8.4 \mathrm{~Hz}, \mathrm{H} 6), 6.65(1 \mathrm{H}, \mathrm{s}$, $\mathrm{PhCH}=\mathrm{C}), 6.87(1 \mathrm{H}, \mathrm{d}, J=8.4 \mathrm{~Hz}, \mathrm{H} 5), 6.93(2 \mathrm{H}, \mathrm{d}, J=8.8 \mathrm{~Hz}$, H3', H5'), 7.34 (2H, d, J=8.8 Hz, H2', H6').

Dimethylamine $(24 \mathrm{mmol})$ and a $37 \%$ formaldehyde solution $(1.56 \mathrm{~g}, 19.0 \mathrm{mmol})$ were dissolved in 1,4-dioxane $(1 \mathrm{~mL})$ and stirred at $45^{\circ} \mathrm{C}$ for $15 \mathrm{~min}$, and then the reaction was added to a solution mixture of compounds $\mathbf{8 a}-\mathbf{c}(16 \mathrm{mmol})$ in $1,4-\mathrm{di}$ oxane $(40 \mathrm{~mL})$. The resulting mixture was stirred and heated at $70^{\circ} \mathrm{C}$ for $30 \mathrm{~min}$, and then it was distilled under reduced pressure until crystals began to form. Compounds 9l-n were collected on a filter and subsequently quaternized by $\mathrm{CH}_{3} \mathrm{Br}$ in acetone to give compounds 101-n. Next, compounds 111-n were prepared by treating the solid containing compounds $\mathbf{1 0 l}-\mathbf{n}(11.7 \mathrm{mmol})$ with an arylamine $(18 \mathrm{mmol})$ in ethanol and using acetic acid as the catalyst. Compounds $111-\mathbf{n}(7.4 \mathrm{mmol})$ in methanol $(60 \mathrm{~mL})$ were reduced to isoflavan-4-ola $11^{\prime} \mathbf{l}-\mathbf{n}$ when treated with $\mathrm{NaBH}_{4}(3.1 \mathrm{~g}, 80 \mathrm{mmol})$ for $48 \mathrm{~h}$ at room temperature, which were dehydrated by reacting with $\mathrm{HCl}$ / EtOH $(5.0 \mathrm{~mL}, 4.5 \mathrm{mmol}, 0.9 \mathrm{~mol} / \mathrm{L})$ to yield a solid containing compounds $12^{\prime} \mathbf{l}-\mathbf{n}$. Lastly, compounds $12^{\prime} \mathbf{l}-\mathbf{n}$ were condensed with paraformaldehyde $(0.14 \mathrm{~g}, 4.5 \mathrm{mmol})$ with potassium hydroxide as a catalyst to give title compounds $\mathbf{1 2 l}-\mathbf{n}$.

12I: Yield $86 \%$; MS $[\mathrm{M}+\mathrm{H}]^{+}(\mathrm{m} / \mathrm{z}): 372.2 ;{ }^{1} \mathrm{H}-\mathrm{NMR}$ $\left(300 \mathrm{MHz}, \mathrm{CDCl}_{3}\right) \delta: 2.19\left(3 \mathrm{H}, \mathrm{s}, \mathrm{PhCH}_{3}\right), 4.51(2 \mathrm{H}, \mathrm{s}$, $\left.\mathrm{PhCH}_{2} \mathrm{~N}\right), 5.13\left(2 \mathrm{H}, \mathrm{s}, \mathrm{OCH}_{2} \mathrm{C}\right), 5.36\left(2 \mathrm{H}, \mathrm{s}, \mathrm{OCH}_{2} \mathrm{~N}\right), 6.31$ $(1 \mathrm{H}, \mathrm{d}, J=8.1 \mathrm{~Hz}, \mathrm{H} 6), 6.77(1 \mathrm{H}, \mathrm{s}, \mathrm{PhCH}=\mathrm{C}), 6.80(2 \mathrm{H}, \mathrm{d}$, $\left.J=8.1 \mathrm{~Hz}, \mathrm{H}^{\prime}, \mathrm{H}^{\prime}\right), 6.89(1 \mathrm{H}, \mathrm{d}, J=8.4 \mathrm{~Hz}, \mathrm{H} 5), 6.99-7.07$ $(4 \mathrm{H}, \mathrm{d} \times 2, \mathrm{NPh}), 7.35\left(2 \mathrm{H}, \mathrm{d}, J=8.4 \mathrm{~Hz}, \mathrm{H} 2^{\prime}, \mathrm{H6}^{\prime}\right)$.

12m: Yield 88\%; MS $[\mathrm{M}+\mathrm{H}]^{+}(\mathrm{m} / \mathrm{z}): 386.1 ;{ }^{1} \mathrm{H}-\mathrm{NMR}$ $\left(300 \mathrm{MHz}, \mathrm{CDCl}_{3}\right) \delta: 2.26\left(3 \mathrm{H}, \mathrm{s}, \mathrm{PhCH}_{3}\right), 3.83(3 \mathrm{H}, \mathrm{s}$, $\left.\mathrm{PhOCH}_{3}\right), 4.54\left(2 \mathrm{H}, \mathrm{s}, \mathrm{PhCH}_{2} \mathrm{~N}\right), 5.13\left(2 \mathrm{H}, \mathrm{s}, \mathrm{OCH}_{2} \mathrm{C}\right), 5.30$ $\left(2 \mathrm{H}, \mathrm{s}, \mathrm{OCH}_{2} \mathrm{~N}\right), 6.38(1 \mathrm{H}, \mathrm{d}, J=8.1 \mathrm{~Hz}, \mathrm{H} 6), 6.63(1 \mathrm{H}, \mathrm{s}$, $\mathrm{PhCH}=\mathrm{C}), 6.84(1 \mathrm{H}, \mathrm{d}, J=7.8 \mathrm{~Hz}, \mathrm{H} 5), 6.91(2 \mathrm{H}, \mathrm{d}, J=8.7 \mathrm{~Hz}$, H3', H5'), 7.02-7.09 (4H, NPh), $7.34\left(2 \mathrm{H}, \mathrm{d}, J=8.7 \mathrm{~Hz}, \mathrm{H} 2^{\prime}\right.$, H6').

12n: Yield 86\%; MS $[\mathrm{M}+\mathrm{H}]^{+}(\mathrm{m} / \mathrm{z}): 369.8 ;{ }^{1} \mathrm{H}-\mathrm{NMR}$ $\left(300 \mathrm{MHz}, \mathrm{CDCl}_{3}\right) \delta: 2.26\left(3 \mathrm{H}, \mathrm{s}, \mathrm{PhCH}_{3}\right), 2.34(3 \mathrm{H}, \mathrm{s}$, $\left.\mathrm{PhCH}_{3}\right), 4.55\left(2 \mathrm{H}, \mathrm{s}, \mathrm{PhCH}_{2} \mathrm{~N}\right), 5.14\left(2 \mathrm{H}, \mathrm{s}, \mathrm{OCH}_{2} \mathrm{C}\right), 5.30$ $\left(2 \mathrm{H}, \mathrm{s}, \mathrm{OCH}_{2} \mathrm{~N}\right), 6.38(1 \mathrm{H}, \mathrm{d}, J=8.4 \mathrm{~Hz}, \mathrm{H} 6), 6.69(1 \mathrm{H}, \mathrm{s}$, $\mathrm{PhCH}=\mathrm{C}), 6.85(1 \mathrm{H}, \mathrm{d}, J=8.4 \mathrm{~Hz}, \mathrm{H} 5), 7.02-7.09(4 \mathrm{H}, \mathrm{d} \times 2$, $\mathrm{NPh}), 7.15\left(2 \mathrm{H}, \mathrm{d}, J=8.1 \mathrm{~Hz}, \mathrm{H} 3^{\prime}, \mathrm{H}^{\prime}\right), 7.30(2 \mathrm{H}, \mathrm{d}, J=8.1 \mathrm{~Hz}$, $\left.\mathrm{H} 2^{\prime}, \mathrm{H6}^{\prime}\right)$.

3-(4-Methoxyphenyl)-9-methyl-2,3,9,10-tetrahydrochromeno $[8,7-e][1,3]$ oxazin- $4(8 H)$-on-es $(13 a-e)$ A methanolic solution of paraformaldehyde $(0.72 \mathrm{~g}, 24.0 \mathrm{mmol})$ and potassium hydroxide platelet was added to the solution mixture of compounds $\mathbf{9 a}-\mathbf{e}(8.0 \mathrm{mmol})$ dissolved in methanol 
$(2.0 \mathrm{~mL})$. Target compounds $\mathbf{1 3 a}-\mathbf{e}$ were separated, filtered and dried under vacuum filtration.

13a: Yield $87 \%$; MS $[\mathrm{M}+\mathrm{H}]^{+}(\mathrm{m} / \mathrm{z}): 340.1 ;{ }^{1} \mathrm{H}-\mathrm{NMR}$ $\left(300 \mathrm{MHz}, \mathrm{CDCl}_{3}\right) \delta: 0.94\left(3 \mathrm{H}, \mathrm{t}, J=7.2 \mathrm{~Hz}, \mathrm{CH}_{3}\right), 1.60(2 \mathrm{H}$, m, $\left.\mathrm{CH}_{2} \mathrm{CH}_{3}\right), 2.69\left(2 \mathrm{H}, \mathrm{t}, J=7.2 \mathrm{~Hz}, \mathrm{NCH}_{2} \mathrm{CH}_{2}\right), 3.95(2 \mathrm{H}, \mathrm{s}$, $\left.\mathrm{PhCH}_{2} \mathrm{~N}\right), 3.87(1 \mathrm{H}, \mathrm{m}, \mathrm{PhCH}), 4.60\left(2 \mathrm{H}, \mathrm{m}, \mathrm{OCH}_{2} \mathrm{C}\right), 4.91$ $\left(2 \mathrm{H}, \mathrm{s}, \mathrm{OCH}_{2} \mathrm{~N}\right), 6.50(1 \mathrm{H}, \mathrm{d}, J=8.7 \mathrm{~Hz}, \mathrm{H} 6), 6.72(2 \mathrm{H}, \mathrm{d}$, $\left.J=8.4 \mathrm{~Hz}, \mathrm{H} 3^{\prime}, \mathrm{H}^{\prime}\right), 7.06\left(2 \mathrm{H}, \mathrm{d}, J=8.1 \mathrm{~Hz}, \mathrm{H} 2^{\prime}, \mathrm{H} 6^{\prime}\right), 7.76$ $(1 \mathrm{H}, \mathrm{d}, J=8.7 \mathrm{~Hz}, \mathrm{H} 5)$.

13b: Yield 90\%; MS $[\mathrm{M}+\mathrm{H}]^{+}(\mathrm{m} / \mathrm{z})$ : 354.2; ${ }^{1} \mathrm{H}-\mathrm{NMR}$ $\left(300 \mathrm{MHz}, \mathrm{CDCl}_{3}\right) \delta: 0.95\left(3 \mathrm{H}, \mathrm{t}, J=7.2 \mathrm{~Hz}, \mathrm{CH}_{3}\right), 1.61(2 \mathrm{H}$, $\left.\mathrm{m}, \mathrm{CH}_{3} \mathrm{CH}_{2}\right), 2.71\left(2 \mathrm{H}, \mathrm{t}, J=7.2 \mathrm{~Hz}, \mathrm{NCH}_{2} \mathrm{CH}_{2}\right), 3.80(3 \mathrm{H}, \mathrm{s}$, $\left.\mathrm{PhOCH}_{3}\right), 3.89(1 \mathrm{H}, \mathrm{m}, \mathrm{PhCH}), 3.97\left(2 \mathrm{H}, \mathrm{s}, \mathrm{PhCH}_{2} \mathrm{~N}\right), 4.62$ $\left(2 \mathrm{H}, \mathrm{m}, \mathrm{OCH}_{2} \mathrm{C}\right), 4.91\left(2 \mathrm{H}, \mathrm{s}, \mathrm{OCH}_{2} \mathrm{~N}\right), 6.50(1 \mathrm{H}, \mathrm{d}, J=8.7 \mathrm{~Hz}$, H6), 6.89 (2H, d, J=8.7 Hz, H3', H5'), $7.19(2 \mathrm{H}, \mathrm{d}, J=8.7 \mathrm{~Hz}$, H2', H6'), 7.77 (1H, d, J=9.0 Hz, H5).

13c: Yield 89\%; MS $[\mathrm{M}+\mathrm{H}]^{+}(\mathrm{m} / \mathrm{z})$ : 395.9; ${ }^{1} \mathrm{H}-\mathrm{NMR}$ $\left(300 \mathrm{MHz}, \mathrm{CDCl}_{3}\right) \delta: 0.88\left(3 \mathrm{H}, \mathrm{t}, J=6.9 \mathrm{~Hz}, \mathrm{CH}_{3}\right), 1.31-1.58$ $\left(8 \mathrm{H}, \mathrm{m}, \mathrm{CH}_{3}\left(\mathrm{CH}_{2}\right)_{4}\right), 2.72\left(2 \mathrm{H}, \mathrm{t}, J=6.9 \mathrm{~Hz}, \mathrm{NCH}_{2} \mathrm{CH}_{2}\right), 3.79$ $\left(3 \mathrm{H}, \mathrm{s}, \mathrm{PhOCH}_{3}\right), 3.88(1 \mathrm{H}, \mathrm{m}, \mathrm{PhCH}), 3.95\left(2 \mathrm{H}, \mathrm{s}, \mathrm{PhCH}_{2} \mathrm{~N}\right)$, $4.62\left(2 \mathrm{H}, \mathrm{m}, \mathrm{OCH}_{2} \mathrm{C}\right), 4.90\left(2 \mathrm{H}, \mathrm{s}, \mathrm{OCH}_{2} \mathrm{~N}\right), 6.50(1 \mathrm{H}, \mathrm{d}$, $J=8.7 \mathrm{~Hz}, \mathrm{H6}), 6.89\left(2 \mathrm{H}, \mathrm{d}, J=8.7 \mathrm{~Hz}, \mathrm{H} 3^{\prime}, \mathrm{H} 5^{\prime}\right), 7.19(2 \mathrm{H}, \mathrm{d}$, $\left.J=8.7 \mathrm{~Hz}, \mathrm{H} 2^{\prime}, \mathrm{H} 6^{\prime}\right), 7.77(1 \mathrm{H}, \mathrm{d}, J=9.0 \mathrm{~Hz}, \mathrm{H} 5)$.

13d: Yield 88\%; MS $[\mathrm{M}+\mathrm{H}]^{+}(\mathrm{m} / \mathrm{z}): 323.8 ;{ }^{1} \mathrm{H}-\mathrm{NMR}$ $\left(300 \mathrm{MHz}, \mathrm{CDCl}_{3}\right) \delta: 1.19\left(3 \mathrm{H}, \mathrm{t}, J=7.2 \mathrm{~Hz}, \mathrm{CH}_{3}\right), 2.32(3 \mathrm{H}$, $\left.\mathrm{s}, \mathrm{PhCH}_{3}\right), 2.79\left(2 \mathrm{H}, \mathrm{q}, J=7.2 \mathrm{~Hz}, \mathrm{NCH}_{2} \mathrm{CH}_{3}\right), 3.80(3 \mathrm{H}, \mathrm{s}$, $\left.\mathrm{PhOCH}_{3}\right), 3.89(1 \mathrm{H}, \mathrm{m}, \mathrm{PhCH}), 3.97\left(2 \mathrm{H}, \mathrm{s}, \mathrm{PhCH}_{2} \mathrm{~N}\right), 4.62$ $\left(2 \mathrm{H}, \mathrm{m}, \mathrm{OCH}_{2} \mathrm{C}\right), 4.91\left(2 \mathrm{H}, \mathrm{s}, \mathrm{OCH}_{2} \mathrm{~N}\right), 6.50(1 \mathrm{H}, \mathrm{d}, J=8.7 \mathrm{~Hz}$, H6), 6.89 (2H, d, J=8.7 Hz, H3', H5'), $7.19(2 \mathrm{H}, \mathrm{d}, J=8.7 \mathrm{~Hz}$, H2', H6' $), 77$ (1H, d, J=9.0 Hz, H5).

13e: Yield 90\%; MS $[\mathrm{M}+\mathrm{H}]^{+}(\mathrm{m} / \mathrm{z}): 386.2 ;{ }^{1} \mathrm{H}-\mathrm{NMR}$ $\left(300 \mathrm{MHz}, \mathrm{CDCl}_{3}\right) \delta: 0.94\left(3 \mathrm{H}, \mathrm{t}, J=7.35 \mathrm{~Hz}, \mathrm{CH}_{3}\right), 1.62(2 \mathrm{H}$, $\left.\mathrm{m}, \mathrm{CH}_{2} \mathrm{CH}_{3}\right), 2.33\left(3 \mathrm{H}, \mathrm{s}, \mathrm{PhCH}_{3}\right), 2.69(2 \mathrm{H}, \mathrm{t}, J=7.5 \mathrm{~Hz}$, $\left.\mathrm{NCH}_{2} \mathrm{CH}_{2}\right), 3.80\left(3 \mathrm{H}, \mathrm{s}, \mathrm{PhOCH}_{3}\right), 3.89(1 \mathrm{H}, \mathrm{m}, \mathrm{PhCH}), 4.00$ $\left(2 \mathrm{H}, \mathrm{s}, \mathrm{PhCH}_{2} \mathrm{~N}\right), 4.64\left(2 \mathrm{H}, \mathrm{m}, \mathrm{OCH}_{2} \mathrm{C}\right), 4.99\left(2 \mathrm{H}, \mathrm{s}, \mathrm{OCH}_{2} \mathrm{~N}\right)$, $6.47(1 \mathrm{H}, \mathrm{d}, J=8.7 \mathrm{~Hz}, \mathrm{H} 6), 7.15$ (4H, s, H3', H5', H2', H6'), $7.77(1 \mathrm{H}, \mathrm{d}, J=8.7 \mathrm{~Hz}, \mathrm{H} 5)$.

6-(7-Methoxy-2H-chromen-3-yl)-3- $\mathrm{R}_{2}-3,4$-dihydro-2Hbenzo[e][1,3]oxazines $(\mathbf{1 8 a}-\mathbf{d})$ Dihydrodaidzein was synthesized according to patent WO9808503A1. Briefly, to a mixture of dihydrodaidzein $(4.0 \mathrm{~g}, 15.7 \mathrm{mmol})$ and sodium bicarbonate $(6.0 \mathrm{~g})$ in acetone $(100 \mathrm{~mL})$ was added dimethyl sulfate $(2.02 \mathrm{~g}, 16 \mathrm{mmol})$ dropwise under stirring at $60^{\circ} \mathrm{C}$, and then the reaction was refluxed for $20 \mathrm{~h}$. After filtration, the filtrate was poured into water $(400 \mathrm{~mL})$ with stirring to give 3-(4-hydroxyphenyl)-7-methoxychroman-4-one (3.78g, $14 \mathrm{mmol})$ as a white solid, which was dissolved in methanol $(50 \mathrm{~mL})$ and treated with $\mathrm{KBH}_{4}(3.02 \mathrm{~g}, 56 \mathrm{mmol})$ at room temperature for $30 \mathrm{~min}$. The reaction was quenched with a saturated ammonium chloride solution $(20 \mathrm{~mL})$ and then ice water $(250 \mathrm{~mL})$; compound $15(3.10 \mathrm{~g}, 11 \mathrm{mmol})$ precipitated as a white solid. Compound $\mathbf{1 5}$ was treated with $\mathrm{HCl} / \mathrm{EtOH}$ $(34.1 \mathrm{~mL}, 0.5 \mathrm{~mol} / \mathrm{L})$ to make the hydroxide radical at the $\mathrm{C}-4$ position. The reaction mixture was left in the refrigerator overnight to crystallize, and compound $16(2.02 \mathrm{~g}, 8 \mathrm{mmol})$ was collected under suction filtration. Next, treatment of compound 16 with a primary amine $(12 \mathrm{mmol})$ and a $37 \%$ formaldehyde solution $(0.78 \mathrm{~g}, 9.6 \mathrm{mmol})$ in 1,4 -dioxane yielded compounds $\mathbf{1 7 a}-\mathbf{d}$, which were reacted with paraformaldehyde $(0.47 \mathrm{~g}, 16 \mathrm{mmol})$ and potassium hydroxide $(0.04 \mathrm{~g}, 0.8 \mathrm{mmol})$ in methanol $(2 \mathrm{~mL})$ at room temperature to obtain title com- pounds $18 \mathbf{a}-\mathbf{d}$.

18a: Yield 70\%; MS $[\mathrm{M}+\mathrm{H}]^{+}(\mathrm{m} / \mathrm{z}): 324.2 ;{ }^{1} \mathrm{H}-\mathrm{NMR}$ $\left(300 \mathrm{MHz}, \mathrm{CDCl}_{3}\right) \delta: 1.18\left(3 \mathrm{H}, \mathrm{t}, J=7.2 \mathrm{~Hz}, \mathrm{CH}_{3}\right), 2.81(2 \mathrm{H}$, q, $\left.J=7.2 \mathrm{~Hz}, \mathrm{NCH}_{2} \mathrm{CH}_{3}\right), 3.79\left(3 \mathrm{H}, \mathrm{s}, \mathrm{PhOCH}_{3}\right), 4.02(2 \mathrm{H}, \mathrm{s}$, $\left.\mathrm{PhCH}_{2} \mathrm{~N}\right), 4.90\left(2 \mathrm{H}, \mathrm{s}, \mathrm{OCH}_{2} \mathrm{C}\right), 5.08\left(2 \mathrm{H}, \mathrm{s}, \mathrm{OCH}_{2} \mathrm{~N}\right), 6.43$ $\left(1 \mathrm{H}, \mathrm{s}, \mathrm{H} 8^{\prime}\right), 6.47\left(1 \mathrm{H}, \mathrm{dd}, J=8.1,2.7 \mathrm{~Hz}, \mathrm{H} 6^{\prime}\right), 6.65(1 \mathrm{H}, \mathrm{s}$, H4'), 6.77 (H, d, J=8.4 Hz, H5'), $6.96(1 \mathrm{H}, \mathrm{s}, \mathrm{H} 5), 7.00(1 \mathrm{H}, \mathrm{d}$, $J=8.7 \mathrm{~Hz}, \mathrm{H} 8), 7.19$ (1H, dd, $J=8.7,2.1 \mathrm{~Hz}, \mathrm{H} 7)$.

18b: Yield 69\%; MS $[\mathrm{M}+\mathrm{H}]^{+}(\mathrm{m} / \mathrm{z}): 338.1 ;{ }^{1} \mathrm{H}-\mathrm{NMR}$ $\left(300 \mathrm{MHz}, \mathrm{CDCl}_{3}\right) \delta: 0.93\left(3 \mathrm{H}, \mathrm{t}, J=7.8 \mathrm{~Hz}, \mathrm{CH}_{3}\right), 1.59(2 \mathrm{H}$, $\left.\mathrm{m}, \mathrm{CH}_{2} \mathrm{CH}_{3}\right), 2.72\left(2 \mathrm{H}, \mathrm{t}, J=7.8 \mathrm{~Hz}, \mathrm{NCH}_{2} \mathrm{CH}_{2}\right), 3.79(3 \mathrm{H}$, $\left.\mathrm{s}, \mathrm{PhOCH}_{3}\right), 4.01\left(2 \mathrm{H}, \mathrm{s}, \mathrm{PhCH}_{2} \mathrm{~N}\right), 4.89\left(2 \mathrm{H}, \mathrm{s}, \mathrm{OCH}_{2} \mathrm{C}\right)$, $5.09\left(2 \mathrm{H}, \mathrm{s}, \mathrm{OCH}_{2} \mathrm{~N}\right), 6.44\left(1 \mathrm{H}, \mathrm{s}, \mathrm{H} 8^{\prime}\right), 6.47(1 \mathrm{H}, \mathrm{dd}, J=8.4$, $\left.2.4 \mathrm{~Hz}, \mathrm{H} 6^{\prime}\right), 6.66\left(1 \mathrm{H}, \mathrm{s}, \mathrm{H} 4^{\prime}\right), 6.78\left(\mathrm{H}, \mathrm{d}, J=8.4 \mathrm{~Hz}, \mathrm{H} 5^{\prime}\right)$, $6.97(1 \mathrm{H}, \mathrm{d}, J=8.4 \mathrm{~Hz}, \mathrm{H} 8), 7.00(1 \mathrm{H}, \mathrm{s}, \mathrm{H} 5), 7.19(1 \mathrm{H}, \mathrm{dd}$, $J=8.4,1.2 \mathrm{~Hz}, \mathrm{H} 7)$.

18c: Yield 75\%; MS $[\mathrm{M}+\mathrm{H}]^{+}(\mathrm{m} / \mathrm{z}): 309.9 ;{ }^{1} \mathrm{H}-\mathrm{NMR}$ $\left(300 \mathrm{MHz}, \mathrm{CDCl}_{3}\right) \delta: 2.62\left(1 \mathrm{H}, \mathrm{s}, \mathrm{NCH}_{3}\right), 3.79(3 \mathrm{H}, \mathrm{s}$, $\left.\mathrm{PhOCH}_{3}\right), 3.98\left(2 \mathrm{H}, \mathrm{s}, \mathrm{PhCH}_{2} \mathrm{~N}\right), 4.82\left(2 \mathrm{H}, \mathrm{s}, \mathrm{OCH}_{2} \mathrm{C}\right), 5.09$ $\left(2 \mathrm{H}, \mathrm{s}, \mathrm{OCH}_{2} \mathrm{~N}\right), 6.44\left(1 \mathrm{H}, \mathrm{d}, J=2.1 \mathrm{~Hz}, \mathrm{H} 8^{\prime}\right), 6.47(1 \mathrm{H}, \mathrm{dd}$, $\left.J=8.4,2.4 \mathrm{~Hz}, \mathrm{H} 6^{\prime}\right), 6.66\left(1 \mathrm{H}, \mathrm{s}, \mathrm{H} 4^{\prime}\right), 6.80(\mathrm{H}, \mathrm{d}, J=8.7 \mathrm{~Hz}$, H8), $6.98\left(1 \mathrm{H}, \mathrm{d}, J=8.1 \mathrm{~Hz}, \mathrm{H} 5^{\prime}\right), 7.01(1 \mathrm{H}, \mathrm{d}, J=1.8 \mathrm{~Hz}, \mathrm{H} 5)$, $7.21(1 \mathrm{H}, \mathrm{dd}, J=8.4,2.1 \mathrm{~Hz}, \mathrm{H} 7)$.

18d: Yield 65\%; MS $[\mathrm{M}+\mathrm{H}]^{+}(\mathrm{m} / \mathrm{z})$ : 337.8; ${ }^{1} \mathrm{H}-\mathrm{NMR}$ $\left(300 \mathrm{MHz}, \mathrm{CDCl}_{3}\right) \delta: 1.17\left(6 \mathrm{H}, \mathrm{d}, J=6.3 \mathrm{~Hz}, \mathrm{CH}\left(\mathrm{CH}_{3}\right)_{2}\right), 3.08-$ $3.16\left(1 \mathrm{H}, \mathrm{m}, J=6.3 \mathrm{~Hz}, \mathrm{NCH}\left(\mathrm{CH}_{3}\right)_{2}\right), 3.79\left(3 \mathrm{H}, \mathrm{s}, \mathrm{PhOCH}_{3}\right)$, $4.09\left(2 \mathrm{H}, \mathrm{s}, \mathrm{PhCH}_{2} \mathrm{~N}\right), 4.98\left(2 \mathrm{H}, \mathrm{s}, \mathrm{OCH}_{2} \mathrm{C}\right), 5.09(2 \mathrm{H}, \mathrm{s}$, $\left.\mathrm{OCH}_{2} \mathrm{~N}\right), 6.43\left(1 \mathrm{H}, \mathrm{d}, J=2.1 \mathrm{~Hz}, \mathrm{H} 8^{\prime}\right), 6.47(1 \mathrm{H}, \mathrm{dd}, J=8.1$, $\left.2.4 \mathrm{~Hz}, \mathrm{H6} 6^{\prime}\right), 6.66\left(1 \mathrm{H}, \mathrm{s}, \mathrm{H} 4^{\prime}\right), 6.76(\mathrm{H}, \mathrm{d}, J=8.7 \mathrm{~Hz}, \mathrm{H} 8), 6.97$ $\left(1 \mathrm{H}, \mathrm{d}, J=8.1 \mathrm{~Hz}, \mathrm{H} 5^{\prime}\right), 7.01(1 \mathrm{H}, \mathrm{d}, J=2.1 \mathrm{~Hz}, \mathrm{H} 5), 7.17(1 \mathrm{H}$, dd, $J=8.4,2.1 \mathrm{~Hz}, \mathrm{H} 7$ ).

Determination of in Vitro Anticancer Activities against SKOV-3 and DU-145 Cell Lines Using a MTT Assay The three cell lines used in this study were cultured in RPMI1640 medium containing sodium bicarbonate $(2.0 \mathrm{~g} / \mathrm{L})$ supplemented with $10 \%(\mathrm{v} / \mathrm{v})$ heat-inactivated $\left(57^{\circ} \mathrm{C}, 40 \mathrm{~min}\right)$ fetal calf serum (FCS), streptomycin $(100 \mu \mathrm{g} / \mathrm{mL})$, penicillin (100 IU/ $\mathrm{mL})$, and L-glutamine $(4 \mu \mathrm{mol} / \mathrm{mL})$; all of these substances were obtained from Serva (Heidelberg, FRG). All of the cell lines were free of pathogenic contaminations during the experiments and were grown as monolayers in a humidified atmosphere $\left(5 \% \mathrm{CO}_{2} / 95 \%\right.$ air $)$ at $37^{\circ} \mathrm{C}$. Exponentially grown cells were plated at $5 \times 10^{4}$ cells $/ \mathrm{cm}^{-2}$ into 96 -well plates and incubated for $24 \mathrm{~h}$. Next, the cells were treated with serial dilutions of the tested compounds at the following final concentrations: $100,30,10,3$ and $1 \mu \mathrm{m}$. Stock solutions of the compounds were initially dissolved in $20 \%$ dimethyl sulfoxide (DMSO) and further diluted with fresh complete medium.

After $72 \mathrm{~h}$ of incubation at $37^{\circ} \mathrm{C}$, the medium was removed and $20 \mu \mathrm{L}$ of MTT reagent $(5 \mathrm{mg} / \mathrm{mL})$ in serum-free medium was added to each well. The plates were incubated at $37^{\circ} \mathrm{C}$ for $4 \mathrm{~h}$. At the end of the incubation period, the medium was removed and pure DMSO $(150 \mu \mathrm{L})$ was added to each well. The metabolized MTT products dissolved in DMSO were quantified by reading their absorbances at $570 \mathrm{~nm}$ using a spectrophotometer. $\mathrm{IC}_{50}$ values (the concentrations of the compounds that caused $50 \%$ cell growth inhibition) were calculated with data processing software (SPSS).

Determinations of in Vitro Anticancer Activities against the HL-60 Cell Line by the Trypan Blue Exclusion Assay Exponentially grown cells were plated at $4 \times 10^{4}$ cells $/ \mathrm{cm}^{-2}$ into 
24-well plates, incubated for $24 \mathrm{~h}$, and then the compounds were added to obtain the following final concentrations: 100, $30,10,3$ and $1 \mu \mathrm{M}$. The vehicle cells were exposed to culture medium containing $0.1 \%$ DMSO. After incubation for $72 \mathrm{~h}$ at $37^{\circ} \mathrm{C}$, the cells were collected and suspended in $0.4 \%$ Trypan blue. The number of viable cells was counted using a hemocytometer, and $\mathrm{IC}_{50}$ values were calculated using data processing software (SPSS).

Acknowledgements The authors thank Dr. Englong Ma's research group at the Shenyang Pharmaceutical University for the use of their in vitro anti-tumor assay.

\section{References}

1) World Health Organization. 〈http://www.who.int/en/».

2) Gupta A., Ray S., Sythesis, 23, 3783-3786 (2008).

3) Banerjee S., Zhang Y., Ali S., Bhuiyan M., Wang Z., Chiao P. J., Philip P. A., Abbruzzese J., Sarkar F. H., Cancer Res., 65, 90649072 (2005).

4) Liu Y., Hu M., Drug Metab. Dispos., 30, 370-377 (2002).

5) Gamble J. R., Xia P., Hahn C. N., Drew J. J., Drogemuller C. J., Brown D., Vadas M. A., Int. J. Cancer, 118, 2412-2420 (2006).

6) Kelly G. E., JOANNOU George Eustace. WO 9808503 A1 (1998).

7) Omura Y., Taruno Y., Irisa Y., Morimoto M., Saimoto H., Shigemasa Y., Tetrahedron Lett., 42, 7273-7275 (2001).

8) Wähälä K., Hase T. A., Heterocycles, 28, 183-186 (1989).

9) Jain A. C, Mehta A., J. Chem. Soc., 1986, 215-220 (1986). 